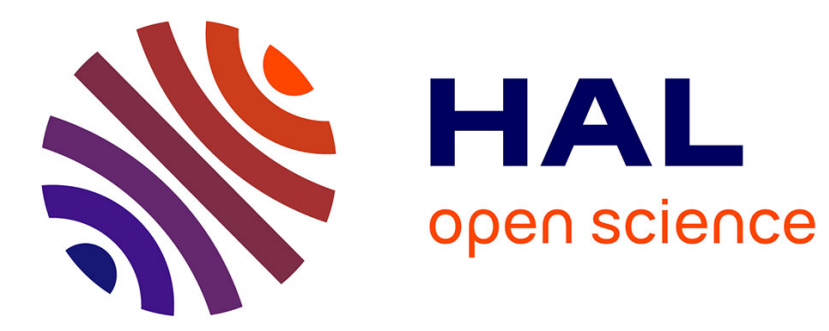

\title{
Pronostic des lymphomes T cutanés érythrodermiques
}

Aude Clement

\section{To cite this version:}

Aude Clement. Pronostic des lymphomes T cutanés érythrodermiques. Médecine humaine et pathologie. 2020. dumas- 03463056

\section{HAL Id: dumas-03463056 https://dumas.ccsd.cnrs.fr/dumas-03463056}

Submitted on 2 Dec 2021

HAL is a multi-disciplinary open access archive for the deposit and dissemination of scientific research documents, whether they are published or not. The documents may come from teaching and research institutions in France or abroad, or from public or private research centers.
L'archive ouverte pluridisciplinaire HAL, est destinée au dépôt et à la diffusion de documents scientifiques de niveau recherche, publiés ou non, émanant des établissements d'enseignement et de recherche français ou étrangers, des laboratoires publics ou privés. 
UNIVERSITÉ CLERMONT AUVERGNE

UFR DE MÉDECINE ET DES PROFESSIONS PARAMÉDICALES

\section{THĖSE D'EXERCICE}

Pour le

DIPLÔME D'ÉTAT DE DOCTEUR EN MÉDECINE

Par

\section{CLEMENT Aude}

Présentée et soutenue publiquement le 15 octobre 2020

Pronostic des lymphomes T cutanés érythrodermiques

Directeur de thèse et président du jury : Monsieur D'INCAN Michel, Professeur, UFR de Médecine et des Professions Paramédicales de Clermont-Ferrand

Membres du jury :

Monsieur TOURNILHAC Olivier, Professeur, UFR de Médecine et des professions paramédicales de Clermont-Ferrand

Monsieur BERGER Marc, Professeur, UFR de Médecine et des professions paramédicales de Clermont-Ferrand

Monsieur ROUANET Jacques, Docteur, UFR de Médecine et des professions paramédicales de Clermont-Ferrand 


\section{UNIVERSITE CLERMONT AUVERGNE}

PRESIDENTS HONORAIRES

UNIVERSITE D'AUVERGNE

PRESIDENTS HONORAIRES

UNIVERSITE BLAISE PASCAL
: JOYON Louis

: DOLY Michel

: TURPIN Dominique

: VEYRE Annie

: DULBECCO Philippe

: ESCHALIER Alain

: CABANES Pierre

: FONTAINE Jacques

: BOUTIN Christian

: MONTEIL Jean-Marc

: ODOUARD Albert

: LAVIGNOTTE Nadine

: BERNARD Mathias : DEQUIEDT Vianney : WILLIAMS Benjamin : HENRARD Pierre : PEYRARD Françoise : PAQUIS François

$$
\diamond \diamond \diamond \diamond \diamond
$$

\section{UFR DE MEDECINE}

\section{ET DES PROFESSIONS PARAMEDICALES}

DOYENS HONORAIRES

: DETEIX Patrice

: CHAZAL Jean

DOYEN

: CLAVELOU Pierre 


\section{LISTE DU PERSONNEL ENSEIGNANT}

\section{PROFESSEURS HONORAIRES :}

MM. BACIN Franck - BEGUE René-Jean - BOUCHER Daniel - BOURGES Michel - BUSSIERE Jean-Louis - CANO Noël - CASSAGNES Jean - CATILINA Pierre - CHABANNES Jacques CHAZAL Jean - CHIPPONI Jacques - CHOLLET Philippe - COUDERT Jean - DASTUGUE Bernard - DAUPLAT Jacques - DECHELOTTE Pierre - DEMEOCQ François - DE RIBEROLLES Charles - ESCANDE Georges -Mme FONCK Yvette - MM. GENTOU Claude - GLANDDIER Gérard - Mme GLANDDIER Phyllis - M. JACQUETIN Bernard - Mme LAVARENNE Jeanine - MM. LAVERAN Henri - LESOURD Bruno - LEVAI Jean-Paul - MAGE Gérard - MALPUECH Georges - MARCHEIX Jean-Claude - MICHEL Jean-Luc - MOLINA Claude - MONDIE Jean-Michel - PERI Georges - PETIT Georges - PHILIPPE Pierre - PLAGNE Robert - PLANCHE Roger - PONSONNAILLE Jean - REY Michel - Mme RIGAL Danièle - MM. ROZAN Raymond - SCHOEFFLER Pierre - SIROT Jacques - SOUTEYRAND Pierre - TANGUY Alain - TERVER Sylvain - THIEBLOT Philippe - TOURNILHAC Michel - VANNEUVILLE Guy - VIALLET Jean-François - Mle VEYRE Annie

\section{PROFESSEURS EMERITES :}

MM. - BEYTOUT Jean - BOITEUX Jean-Paul - BOMMELAER Gilles - CHAMOUX Alain DETEIX Patrice - DUBRAY Claude - ESCHALIER Alain - IRTHUM Bernard - KEMENY JeanLouis - LABBE André - Mme LAFEUILLE Hélène - MM. LEMERY Didier - LUSSON Jean- René - RIBAL Jean-Pierre

\section{PROFESSEURS DES UNIVERSITES-PRATICIENS HOSPITALIERS}

PROFESSEURS DE CLASSE

EXCEPTIONNELLE

M. VAGO Philippe

M. AUMAITRE Olivier

M. LABBE André

M. AVAN Paul

M. DURIF Franck

M. BOIRE Jean-Yves

M. BOYER Louis

M. POULY Jean-Luc

M. CANIS Michel

Mme PENAULT-LLORCA Frédérique

M. BAZIN Jean-Etienne

M. BIGNON Yves Jean

M. BOIRIE Yves

M. CLAVELOU Pierre
Histologie-Embryologie Cytogénétique Médecine Interne

Pédiatrie

Biophysique et Traitement de l'Image

Neurologie

Biostatistiques, Informatique Médicale et Technologies de Communication Radiologie et Imagerie Médicale option Clinique Gynécologie et Obstétrique Gynécologie-Obstétrique Anatomie et Cytologie Pathologiques Anesthésiologie et Réanimation Chirurgicale

Cancérologie option Biologique Nutrition Humaine Neurologie 
M. DUBRAY Claude

M. GILAIN Laurent

M. LEMAIRE Jean-Jacques

M. CAMILLERI Lionel

M. DAPOIGNY Michel

M. LLORCA Pierre-Michel

M. PEZET Denis

M. SOUWEINE Bertrand

M. BOISGARD Stéphane

Mme DUCLOS Martine

M. SCHMIDT Jeannot

M. BERGER Marc

M. GARCIER Jean-Marc

M. ROSSET Eugénio

M. SOUBRIER Martin
Pharmacologie Clinique

O.R.L.

Neurochirurgie

Chirurgie Thoracique et Cardio-Vasculaire

Gastro-Entérologie

Psychiatrie d'Adultes

Chirurgie Digestive

Réanimation Médicale

Chirurgie Orthopédique et Traumatologie

Physiologie

Thérapeutique

Hématologie

Anatomie-Radiologie et Imagerie Médicale Chirurgie Vasculaire

Rhumatologie
PROFESSEURS DE

1ère CLASSE
M. CAILLAUD Denis

M. VERRELLE Pierre

M. CITRON Bernard

M. D'INCAN Michel

Mme JALENQUES Isabelle

Mle BARTHELEMY Isabelle

M. GERBAUD Laurent

M. TAUVERON Igor

M. MOM Thierry

M. RICHARD Ruddy

M. RUIVARD Marc

M. SAPIN Vincent

M. BAY Jacques-Olivier

M. COUDEYRE Emmanuel

Mme GODFRAIND Catherine

M. ABERGEL Armando

M. LAURICHESSE Henri

M. TOURNILHAC Olivier

M. CHIAMBARETTA Frédéric

M. FILAIRE Marc

M. GALLOT Denis

M. GUY Laurent

M. TRAORE Ousmane

M. ANDRE Marc

M. BONNET Richard

M. CACHIN Florent

M. COSTES Frédéric

M. FUTIER Emmanuel

Mme HENG Anne-Elisabeth

M. MOTREFF Pascal

Mme PICKERING Gisèle

M. RABISCHONG Benoît
Pneumo-phtisiologie

Radiothérapie option Clinique

Cardiologie et Maladies Vasculaires

Dermatologie -Vénéréologie

Psychiatrie d'Adultes

Chirurgie Maxillo-Faciale

Epidémiologie, Economie de la Santé

et Prévention

Endocrinologie et Maladies Métaboliques

Oto-Rhino-Laryngologie

Physiologie

Médecine Interne

Biochimie et Biologie Moléculaire

Cancérologie

Médecine Physique et de Réadaptation

Anatomie et Cytologie Pathologiques

Hépatologie

Maladies Infectieuses et Tropicales

Hématologie

Ophtalmologie

Anatomie - Chirurgie Thoracique et

Cardio-Vasculaire

Gynécologie-Obstétrique

Urologie

Hygiène Hospitalière

Médecine Interne

Bactériologie, Virologie

Biophysique et Médecine Nucléaire

Physiologie

Anesthésiologie-Réanimation

Néphrologie

Cardiologie

Pharmacologie Clinique

Gynécologie Obstétrique 
Mme CREVEAUX Isabelle

M. FAICT Thierry

Mme KANOLD LASTAWIECKA Justyna

M. TCHIRKOV Andréï

M. CORNELIS François

M. DESCAMPS Stéphane

M. POMEL Christophe

M. CANAVESE Fédérico

M. LESENS Olivier

M. AUTHIER Nicolas

M. BROUSSE Georges

M. BUC Emmanuel

M. CHABROT Pascal

M. LAUTRETTE Alexandre

M. AZARNOUSH Kasra

Mme BRUGNON Florence

Mme HENQUELL Cécile

M. ESCHALIER Romain

M. MERLIN Etienne

Mme TOURNADRE Anne

M. DURANDO Xavier

M. DUTHEIL Frédéric

Mme FANTINI Maria Livia

M. SAKKA Laurent

M. BOURDEL Nicolas

M. GUIEZE Romain

M. POINCLOUX Laurent

M. SOUTEYRAND Géraud

M. EVRARD Bertrand

M. POIRIER Philippe
Biochimie et Biologie Moléculaire

Médecine Légale et Droit de la Santé

Pédiatrie

Cytologie et Histologie

Génétique

Chirurgie Orthopédique et Traumatologique

Cancérologie - Chirurgie Générale

Chirurgie Infantile

Maladies Infectieuses et Tropicales

Pharmacologie Médicale

Psychiatrie Adultes/Addictologie

Chirurgie Digestive

Radiologie et Imagerie Médicale

Néphrologie Réanimation Médicale

Chirurgie Thoracique et Cardiovasculaire

Biologie et Médecine du Développement et

de la Reproduction

Bactériologie Virologie

Cardiologie

Pédiatrie

Rhumatologie

Cancérologie

Médecine et Santé au Travail

Neurologie

Anatomie - Neurochirurgie

Gynécologie-Obstétrique

Hématologie

Gastroentérologie

Cardiologie

Immunologie

Parasitologie et Mycologie

\section{PROFESSEURS DES UNIVERSITES}

M. CLEMENT Gilles

Mme MALPUECH-BRUGERE Corinne

M. VORILHON Philippe
Médecine Générale

Nutrition Humaine

Médecine Générale

\section{PROFESSEURS ASSOCIES DES UNIVERSITES}

Mme BOTTET-MAULOUBIER Anne

M. CAMBON Benoît

M. TANGUY Gilles
Médecine Générale

Médecine Générale

Médecine Générale 


\section{MAITRES DE CONFERENCES DES UNIVERSITES - PRATICIENS HOSPITALIERS}

\section{MAITRES DE CONFERENCES}

HORS CLASSE

Mme CHAMBON Martine

Mme BOUTELOUP Corinne
Bactériologie Virologie

Nutrition

\section{MAITRES DE CONFERENCES DE 1ère}

CLASSE

M. MORVAN Daniel

Mle GOUMY Carole

Mme FOGLI Anne

Mle GOUAS Laetitia

M. MARCEAU Geoffroy

Mme MINET-QUINARD Régine

M. ROBIN Frédéric

Mle VERONESE Lauren

M. DELMAS Julien

Mle MIRAND Audrey

M. OUCHCHANE Lemlih

M. LIBERT Frédéric

Mle COSTE Karen

Mle AUMERAN Claire

Mme CASSAGNES Lucie

M. LEBRETON Aurélien

M. BUISSON Anthony
Biophysique et Traitement de l'Image Cytologie et Histologie, Cytogénétique Biochimie Biologie Moléculaire Cytologie et Histologie, Cytogénétique Biochimie Biologie Moléculaire Biochimie Biologie Moléculaire Bactériologie

Cytologie et Histologie, Cytogénétique Bactériologie

Bactériologie Virologie

Biostatistiques, Informatique Médicale et Technologies de Communication Pharmacologie Médicale Pédiatrie

Hygiène Hospitalière Radiologie et Imagerie Médicale Hématologie Gastroentérologie

\section{MAITRES DE CONFERENCES DE 2ème}

CLASSE

Mme PONS Hanaë

M. JABAUDON-GANDET Matthieu

M. BOUVIER Damien

M. COLL Guillaume

Mme SARRET Catherine

M. MAQDASY Salwan

Mme NOURRISSON Céline
Biologie et Médecine du Développement et de la Reproduction

Anesthésiologie - Réanimation Chirurgicale Biochimie et Biologie Moléculaire

Neurochirurgie

Pédiatrie

Endocrinologie, Diabète et Maladies

Métaboliques

Parasitologie - Mycologie 


\section{MAITRES DE CONFERENCES DES UNIVERSITES}

Mme VAURS-BARRIERE Catherine

M. BAILLY Jean-Luc

Mle AUBEL Corinne

M. BLANCHON Loïc

Mle GUILLET Christelle

M. BIDET Yannick

M. MARCHAND Fabien

M. DALMASSO Guillaume

M. SOLER Cédric

M. GIRAUDET Fabrice

1'Image Mme VAILLANT-ROUSSEL Hélène

Mme LAPORTE Catherine

M. LOLIGNIER Stéphane

Mme MARTEIL Gaëlle

M. PINEL Alexandre

M. PIZON Frank
Biochimie Biologie Moléculaire

Bactériologie Virologie

Oncologie Moléculaire

Biochimie Biologie Moléculaire

Nutrition Humaine

Oncogénétique

Pharmacologie Médicale

Bactériologie

Biochimie Biologie Moléculaire

Biophysique et Traitement de

Médecine Générale

Médecine Générale

Neurosciences - Neuropharmacologie

Biologie de la Reproduction

Nutrition Humaine

Santé Publique

\section{MAITRES DE CONFERENCES ASSOCIES DES UNIVERSITES}

M. BERNARD Pierre

Mme ESCHALIER Bénédicte

Mme RICHARD Amélie

M. TESSIERES Frédéric
Médecine Générale

Médecine Générale

Médecine Générale

Médecine Générale 


\title{
AU PRESIDENT DU JURY
}

\author{
Monsieur le Professeur Michel D'INCAN
}

Je vous remercie de m'avoir proposé ce travail et de l'avoir dirigé. C'est un honneur pour moi de pouvoir bénéficier de votre expérience et de travailler avec vous sur les lymphomes cutanés. Au cours de ces cinq années d'internat, votre savoir et votre passion m'ont permis d'acquérir de nombreuses connaissances en dermatologie.

\section{AUX MEMBRES DU JURY}

\author{
Monsieur le Professeur Olivier TOURNILHAC
}

Vous me faites l'honneur de siéger dans ce jury de thèse. Je vous suis reconnaissante d'apporter vos connaissances dans le domaine des lymphomes, à la critique de ce travail. Veuillez croire en l'expression de ma respectueuse considération.

\section{Monsieur le Professeur Marc BERGER}

Je vous remercie d'avoir accepté de faire partie de ce jury de thèse. Votre spécialité étant d'une aide inestimable dans la prise en charge des lymphomes cutanés, je suis honorée de votre participation à la critique de mon travail. Veuillez trouver ici l'expression de mon profond respect.

\section{Monsieur le Docteur Jacques ROUANET}

Je te remercie pour ta présence au sein de ce jury de thèse, mais également pour ton aide au quotidien dans le service. Merci d'avoir pris du temps pour lire et juger mon travail. 


\section{REMERCIEMENTS}

A mes parents, pour m'avoir toujours soutenue, quels que soient mes choix et mes changements de direction durant ces nombreuses années d'étude. Pour avoir toujours eu confiance en moi, et m'avoir appris à ne jamais renoncer.

A mon frère, auprès de qui j'ai toujours appris et continue sans cesse d'apprendre, et qui malgré la distance, est toujours présent pour moi. Je suis fière de toi, et j'espère te rendre fier.

A Papinou, mon grand-père, dont la présence a toujours été importante à toutes les étapes de ma vie, et notamment pendant mes études, et qui n'a jamais douté de moi.

A Mathilde, ma cothurne, grâce à qui la P1 a semblé moins difficile, avec qui j'ai eu les plus grands fous rires mais aussi les pires coups de blues. Je suis fière du chemin que nous avons parcouru.

A Vanina, Julie et Mathieu, pour m'avoir supportée pendant nos folles années à la Boâte.

A Manu, Jerem et Aude, et leur aide durant mes premiers pas en tant qu'interne à Aurillac.

A toute la team du Puy, et ce semestre d'été inoubliable, merci de toujours répondre présent quand j'ai besoin de vous.

A Monsieur et Madame Favre, pour leur bienveillance, leur confiance, et toutes les connaissances qu'ils m'ont apportées. A tout le service de Dermatologie du Puy, à leur accueil chaleureux et à leur bonne humeur.

A Madame Dorcier, pour avoir partagé son savoir, et m'avoir appris à toujours être rigoureuse dans mon travail. A toute l'équipe de Dermatologie d'Aurillac, qui ont toujours su me soutenir, et notamment à Sandrine, Agnès et Valérie, mes anges gardiens.

A Carole et Fanny, pour m'avoir accueillie en anatomopathologie, et m'avoir fait découvrir leur spécialité avec patience et bienveillance.

A Cécilia, ma première rencontre de la famille des Dermatojolies, qui m'a accueillie à bras ouverts et avec qui j'aime toujours discuter et partager des potins.

A Justine, avec qui j'apprends tous les jours, entre deux fous rires en consultation. Tu es une véritable amie, mais aussi un modèle pour moi. J'ai hâte de continuer à travailler avec toi.

A Marie, qui m'a appris à prendre confiance en moi quand je suis arrivée au $\mathrm{CHU}$, entre deux fables de La Fontaine.

A mes co-internes, Charline et sa répartie légendaire, à Clotilde ma beauty queen, à Pauline la dresseuse Pokemon, à Inès et sa merco benz benz, à Elise et sa constante bonne humeur, à Elodie ma co-équipière de buffet, mais aussi à Iris, Emmanuelle et Jean-Baptiste, même si je n'ai pas encore eu l'occasion de travailler avec vous.

A Mélanie, Camille, Lulu, et Clemclem, pour tous les bons moments partagés dans le service et en dehors. 


\section{TABLE DES MATIERES}

Introduction

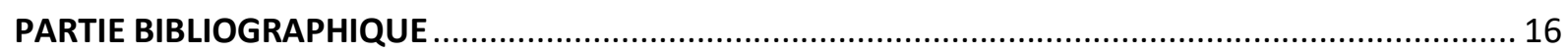

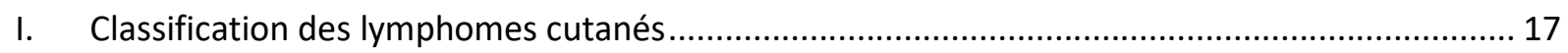

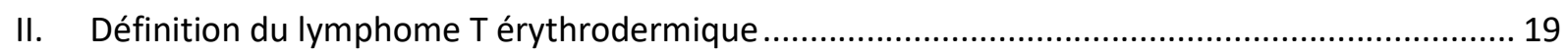

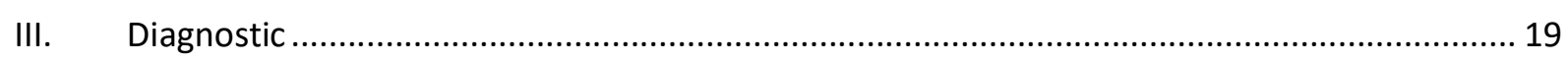

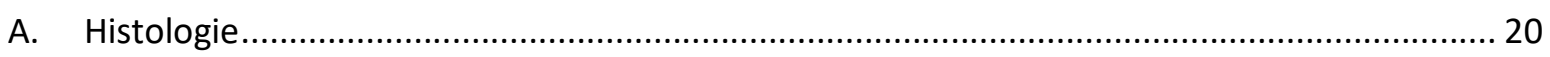

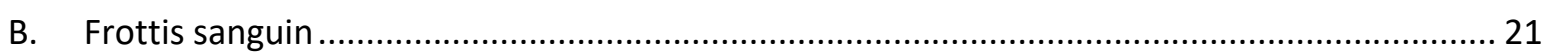

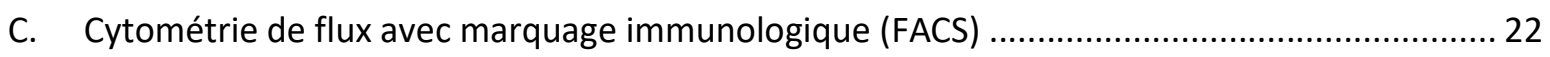

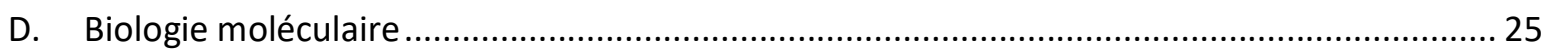

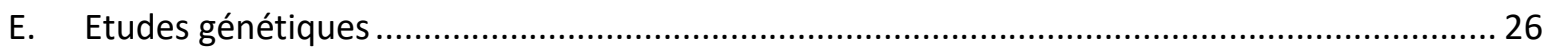

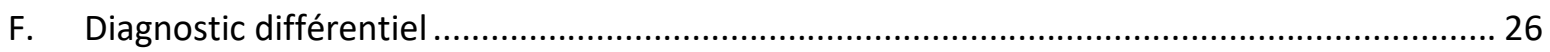

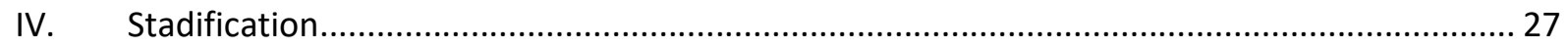

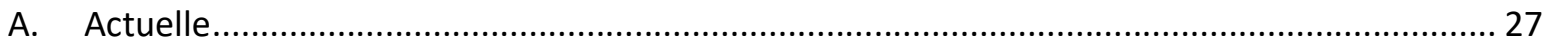

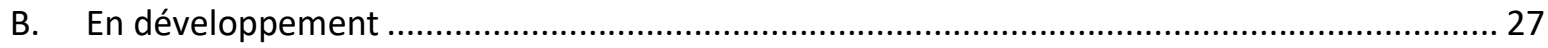

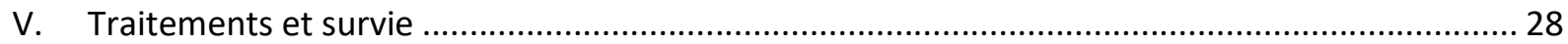

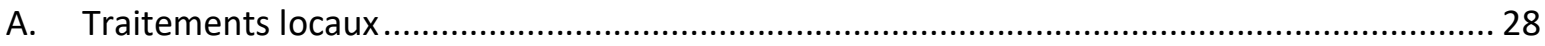

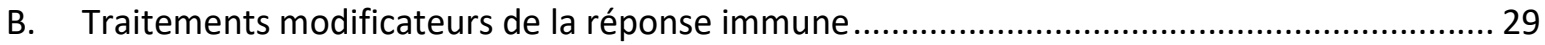

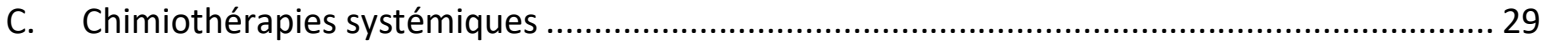

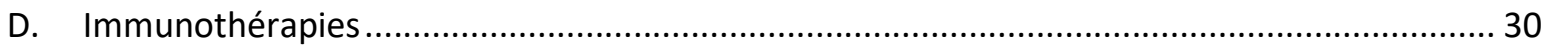

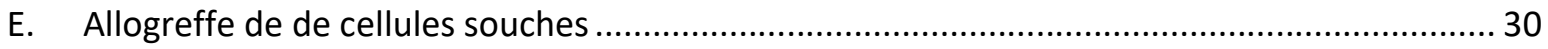

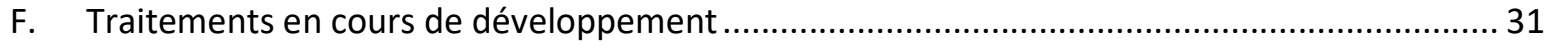

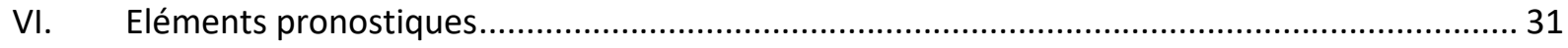

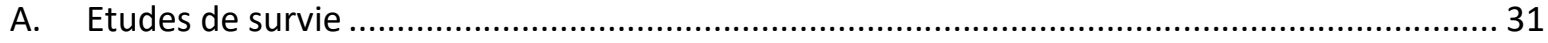

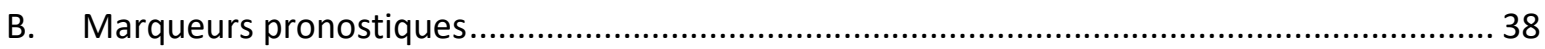

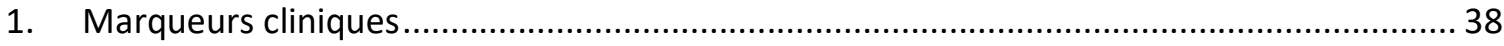

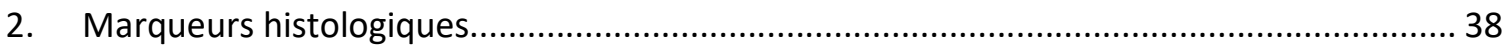

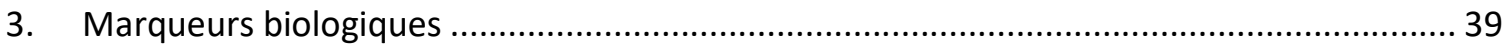

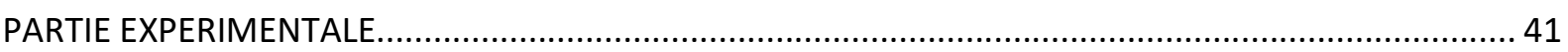

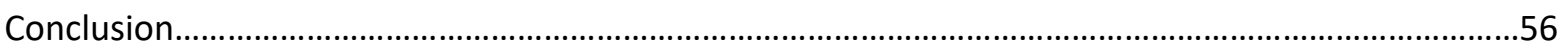




\section{TABLEAUX ET FIGURES}

\section{Partie bibliographique :}

Tableau 1 : Classification EORTC/ISCL 2007 des lymphomes cutanés de type MF/SS (Page 15)

Tableau 2 : Révision 2018 de la classification OMS/EORTC des lymphomes T cutanés (Page 18)

Tableau 3 : Stadification $\mathrm{H}$ de l'atteinte sanguine (Page 33)

Tableau 4 : Propositions de stadification sanguine des lymphomes cutanés érythrodermiques (Page 34)

Tableau 5 : Comparatif des différentes études de survie au cours des années (Page 37)

\section{Partie expérimentale :}

Tableau 1 : Classification PROCLIPI proposée par I'EORTC (Page 47)

Tableau 2 : Classification EORTC/ISCL 2007 des lymphomes cutanés de type MF/SS (Page 48)

Tableau 3 : Caractéristiques clinico-biologiques des 52 patients, à la date du diagnostic (Page 49)

Tableau 4 : Facteurs clinico-biologiques associés à la survie globale des patients (Page 50)

Tableau 5 : Caractéristiques clinico-biologiques des patients ayant changé de stade B au cours du suivi (Page 51)

Figure 1 : Diagramme de flux des patients de l'étude (Page 52)

Figure 2 : Répartition des patients en stade B (Page 52)

Figure 3 : Courbe de survie globale des 52 patients, quel que soit le stade B initial (Page 53)

Figure 4 : Courbes de survie globale des 52 patients, selon le stade B initial (Page 53)

Figure 5 : Courbe de survie spécifique des 41 patients, quel que soit le stade B initial (Page 54)

Figure 6 : Courbes de survie spécifique des 41 patients, selon le stade B initial (Page 54) 


\section{ABREVIATIONS}

$C D$ : Cluster de différenciation

CHU : Centre Hospitalier Universitaire

EORTC : European Organisation for Research and Treatment of Cancer

FACS : Fluorescence Activated Cell Sorting

GVH : Greffon Versus Host

HDAC : Histone Dé-Acétylase

IL : Interleukine

ISCL : International Society for Cutaneous Lymphoma

KIR : Killer cell Immunoglobuline-like Receptor

LCP : lymphome cutané primitif

LT : lymphome T

LTC : Iymphome T cutané

LTCE : lymphome T cutané érythrodermique

MF : Mycosis fongoïde

MFCG : Mycosis Fungoides Cooperative Group

NK : Natural Killer

OMS : Organisation Mondiale de la Santé

PCR : Polymerase Chain Reaction

PO : Per Os

PROCLIPI: Prospective Cutaneous Lymphoma International Prognostic Index study PRP : Pityriasis rubra pilaire

SS : Syndrome de Sézary

TCR : T cell receptor

TNM : classification des cancers (Tumeur Node Métastase)

WHO : World Health Organization 


\section{Introduction}

Les lymphomes cutanés regroupent un ensemble de pathologies hétérogènes, qui sont, après les lymphomes digestifs, la localisation la plus fréquente des lymphomes extra ganglionnaires. On distingue les lymphomes cutanés à cellules " B » et les lymphomes à cellules " $T$ ", ces derniers étant plus fréquents (75\%).

En 2005, le consortium EORTC/ISCL a identifié les lymphomes T érythrodermiques au sein des lymphomes T cutanés (1). Ces lymphomes ont pour caractéristique celle de se présenter cliniquement sous la forme d'une érythrodermie (érythème de la quasi-totalité du corps évoluant sur plusieurs semaines). En effet, jusqu'alors, les lymphomes cutanés T avec érythrodermie reconnus étaient, le mycosis fongoïde érythrodermique et le syndrome (maladie) de Sézary. Ce dernier répondait à des critères biologiques précis : plus de 1000 cellules tumorales circulantes par microlitre, dites cellules de Sézary, et un rapport entre les populations lymphocytaires sanguines CD4+ et CD8+ supérieur à 10.

En fait, il est apparu que cette dichotomie était trop réductrice car le syndrome de Sézary correspondait à une forme de lymphome comportant une charge tumorale importante, notamment circulante. Le mycosis fongoïde érythrodermique lui, ne s'accompagnait pas, ou alors qu'en faible quantité, de cellules tumorales circulantes. Et en pratique courante, nombre de situations intermédiaires existaient. Ainsi, le concept de lymphomes érythrodermiques est né, avec une classification en trois groupes, B0, B1 et B2, selon l'importance de la charge tumorale circulante (tableau 1). Le groupe BO correspond à l'ancien mycosis fongoïde 
érythrodermique, le groupe B2 au syndrome de Sézary, le groupe B1 étant un stade intermédiaire (2).

Le pronostic des lymphomes T cutanés érythrodermiques (LTCE) est varié. De nombreux travaux ont tenté d'identifier des facteurs, ou des combinaisons de facteurs pronostiques, cytologiques, immunohistologiques ou moléculaires, mais très peu d'études ont spécifiquement analysé la valeur pronostique de la classification en stades B, pourtant utilisée au quotidien par le clinicien. Les études de survie basées sur cette classification ont conduit à des résultats souvent contradictoires.

Dans notre travail, nous avons repris une série de patients, issus du service de Dermatologie du CHU de Clermont-Ferrand, porteurs d'un LTCE, les avons classés selon les stades B et avons étudié leur pronostic.

Dans une première partie bibliographique de ce travail, je ferai un rappel sur les lymphomes T cutanés érythrodermiques, leur place parmi les lymphomes cutanés, leurs caractéristiques cliniques, les moyens de diagnostic, puis, dans une seconde partie expérimentale, je présenterai les résultats de notre étude. 
Tableau 1 : Classification EORTC/ISCL 2007 des lymphomes cutanés de type MF/SS

$T$ : atteinte cutanée

T1: lésions cutanées limitées érythémateuses non infiltrées, papules ou plaques < $10 \% 5 \mathrm{~S}$ :

T1a: lésions érythémateuses non infiltrées (patches)

T1b: plaques

T2: lésions cutanées érythémateuses non infiltrées, papules ou plaques $>10 \%$ SC:

$\mathrm{T} 2 \mathrm{a}$ : lésions érythémateuses non infiltrées (patches)

T2b: plaques

T3: une ou plusieurs tumeurs (une tumeur est définie par une taille $>$ à $1 \mathrm{~cm}$ )

T4: érythrodermie (surface corporelle atteinte $>80 \%$ ).

$N$ : statut ganglionnaire

NO: pas d'adénopathie périphérique palpable

N1 : adénopathie périphérique palpable, histologie grade 1 allemand ou NCI LNO-2:

N1a: pas de clone

N1b: clone+

N2: adénopathie périphérique palpable, histologie grade 2 allemand ou NCI LN3:

$\mathrm{N} 2 \mathrm{a}$ : pas de clone

$\mathrm{N} 2 \mathrm{~b}$ : clone +

N3: adénopathie périphérique palpable, histologie grade $3-4$ allemand ou NCI LN4, clone +1-

$\mathrm{Nx}$ : adénopathie périphérique palpable, pas d'histologie de confirmation

$M$ : statut viscéral

MO: pas d'atteinte viscérale

M1 : atteinte viscérale (à documenter histologiquement)

B: atteinte sanguine

B0: $<5 \%$ de cellules de Sézary circulantes:

$\mathrm{BOa}$ : pas de clone

BOb: clone +

B1: $>5 \%$ de cellules de Sézary circulantes $<1000 / \mu \mathrm{L}$

B1a: pas de clone

B1b: clone +

B2: cellules de Sézary $>1000 / \mu \mathrm{L}$ avec un clone T majoritaire

\begin{tabular}{|c|c|c|c|c|}
\hline Soit la stadification & T & $\mathrm{N}$ & M & B \\
\hline IA (plaques infiltrées ou non< $10 \%$ surface corporelle) & 1 & 0 & 0 & 0 \\
\hline IB (plaques infiltrées ou non $>10 \%$ surface corporelle) & 2 & 0 & 0 & 0 \\
\hline $\begin{array}{l}\text { IIA (plaques infiltrées ou non avec adénopathie } \\
\text { périphérique palpable, histologiquement non } \\
\text { spécifique) }\end{array}$ & 1,2 & 1,2 & 0 & 0 \\
\hline IIB (tumeurs) & 3 & 0 à 2 & 0 & 0 \\
\hline IIIA (érythrodermie sans envahissement sanguin) & 4 & 0 à 2 & 0 & 0 \\
\hline IIIB (érythrodermie avec envahissement sanguin timité) & 4 & 0 à 2 & 0 & 1 \\
\hline $\begin{array}{l}\text { IVA1 (envahissement sanguin important sans } \\
\text { adénopathie spécifique) }\end{array}$ & 1 à 4 & 0 à 2 & 0 & 2 \\
\hline IVA2 (adénopathie spécifique) & 1 à 4 & 3. & 0 & 0 à 2 \\
\hline IVB (atteinte viscérale) & 1 à 4 & 0 à 3 & 1 & 0 à 2 \\
\hline
\end{tabular}

SC: surface corporelle; EORTC: European Organization for Research and Treatment of Cancer; ISCL: International society for cutaneous lymphoma; MF: syndrome de Sézary; SS: syndrome de Sézary. 
PARTIE

BIBLIOGRAPHIQUE 


\section{Classification des lymphomes cutanés}

Les lymphomes cutanés constituent un groupe de lymphomes non Hodgkiniens dont l'expression cutanée est, soit exclusive (c'est le cas dans la quasi-totalité des cas), soit suivie, plusieurs mois après son apparition, de localisations ganglionnaires, ou très rarement viscérales. Cette définition les oppose aux lymphomes ganglionnaires comportant, secondairement, des localisations cutanées.

Après les lymphomes digestifs, les lymphomes cutanés représentent la localisation la plus fréquente de lymphomes extra-ganglionnaires. Contrairement à ces derniers, les lymphomes T représentent la majorité des lymphomes cutanés (75\%) (3).

Depuis plus de 20 ans, les classifications des lymphomes cutanés se sont multipliées ou se sont modifiées. Actuellement c'est la classification OMS/EORTC revue en 2018 qui prévaut (tableau 2). Schématiquement, les lymphomes $T$ sont représentés majoritairement par le mycosis fongoïde et ses formes apparentées. 
Tableau 2 : Révision 2018 de la classification OMS/EORTC des lymphomes T cutanés

Mycosis Fongoïde

Variantes du MF

MF pilotrope

Lymphome pagétoïde

Lymphome chalazodermique

Syndrome de Sézary

Leucémie/lymphome de l'adulte

Lymphoproliférations CD30+

Lymphome cutané à grandes cellules anaplasiques

Papulose lymphomatoïde

Lymphome sous-cutané à type de panniculite

Lymphome cutané à cellules NK, type nasal

Infection chronique à l'EBV

Entités rares de lymphomes T cutanés primitifs

Lymphome $\mathrm{T}$ cutané à cellules gamma delta +

Lymphome $\mathrm{T}$ épidermotrope agressif $\mathrm{CD} 8+$

Lymphome $\mathrm{T}$ pléiomorphe à petites et moyennes cellules $\mathrm{CD} 4+$

Lymphome $\mathrm{T}$ acral à cellules $\mathrm{CD} 8+$

Lymphome T cutané périphérique, sans spécificité 


\section{Définition du lymphome T érythrodermique}

II se caractérise par une érythrodermie, définie par un érythème affectant plus de $90 \%$ de la surface corporelle, et évoluant généralement depuis plus de 6 semaines. Elle est œdémateuse ou squameuse, associée à un prurit. Elle s'installe rapidement, en quelques semaines, et des troubles de la thermorégulation sont fréquemment associés. Après plusieurs mois d'évolution, apparaissent des signes secondaires: une dépilation avec alopécie, une kératodermie palmoplantaire, un ectropion, et une onychodystrophie. Des adénomégalies superficielles sont aussi fréquemment retrouvées (4).

\section{Diagnostic}

Le diagnostic des lymphomes cutanés repose sur la confrontation de données cliniques, histologiques et moléculaires. La médiane de délai diagnostique est de 4,2 ans, avec un intervalle de 1 mois à 32 ans. Les patients avec un diagnostic précoce sont généralement plus âgés et présentent une érythrodermie typique (5).

Différentes définitions diagnostiques ont été proposées ces dernières années, ce qui montre la difficulté à établir un diagnostic certain chez ces patients érythrodermiques (6) :

- Définition de l'EORTC : ratio CD4/CD8 >10, avec une lymphocytose CD4+ et un clone cellulaire T circulant,

- Définition de la WHO : compte de cellules de Sézary $>1 \times 10^{\wedge} 9 / L$, associé à d’autres critères non définis précisément,

- Définition adoptée par les deux organismes : définition du stade B2 (tableau 1) selon I'ISCL, associé à un clone cellulaire T dans la peau et le sang. 


\section{A. Histologie}

L'histologie est souvent similaire à celle du mycosis fongoïde, avec un infiltrat lymphocytaire

T dans le derme superficiel, en bande sous-épidermique. II est fait de lymphocytes atypiques, avec des noyaux parfois cérébriformes, et qui tendent à migrer au sein de l'épiderme (épidermotropisme) de façon isolée ou sous forme de thèques (micro-abcès de Pautrier). Cependant, dans presque $40 \%$ des cas, l'aspect histologique est moins spécifique. Ainsi, dans la plupart des études réalisées, le diagnostic étiologique de l'érythrodermie par simple analyse histologique n'est possible que dans $66 \%$ des cas $(4,7)$. En effet, l'épidermotropisme est souvent absent dans le LTCE, ainsi que d'autres critères (habituellement retrouvés dans le MF), comme l'alignement des cellules atypiques le long de la membrane basale, et l'aspect cérébriforme du noyau (8). L'histologie est donc souvent non spécifique, retrouvant une simple spongiose ou une dermatose psoriasiforme. Seule la présence de micro-abcès de Pautrier serait pathognomonique du diagnostic d'érythrodermie lymphomateuse, mais ceuxci ne sont retrouvés que dans 20 à $30 \%$ des cas $(9,10)$. La confrontation anatomoclinique est donc essentielle, et il paraît nécessaire dans le contexte de réaliser des biopsies multiples, notamment dans les formes où l'infiltrat risque d'être discret et difficile à distinguer d'éléments inflammatoires réactionnels (4).

La problématique de l'analyse histologique des lymphomes cutanés est donc double, car elle doit permettre de faire le diagnostic différentiel avec un infiltrat inflammatoire réactionnel ou une hémopathie non lymphoïde, puis de classer correctement le lymphome au sein de la classification OMS.

L'analyse histologique doit être complétée par une étude immunohistochimique, permettant de caractériser la nature lymphoïde de l'infiltrat, puis de distinguer le phénotype B ou T avec 
éventuellement caractérisation auxiliaire CD4+ (dans le cas du lymphome T érythrodermique), CD8+, etc... Dans le LTCE, l'immunohistochimie met en évidence des lymphocytes CD3+, CD4+, CD8-, avec une différenciation de type T auxiliaire, mais peut présenter un trou phénotypique sur certains antigènes pan- $T(C D 2, C D 5 \ldots)$. La perte d'expression du CD7 sur plus de $50 \%$ de l'infiltrat, associée à une expression de CD8 + inférieure à 25\%, est très en faveur du diagnostic de LTCE. Le marquage par le Ki 67 et MUM-1 peuvent également être utilisés, et sont souvent positifs dans les lymphomes T cutanés (10).

En cas d'adénomégalie de taille supérieure à $2 \mathrm{~cm}$, une histologie ganglionnaire doit être faite, mais elle retrouve le plus souvent un aspect de lymphadénopathie dermatopathique non spécifique, ne permettant pas de faire la différence avec une autre dermatose réactionnelle inflammatoire (8).

\section{B. Frottis sanguin}

En complément de l'histologie, des examens biologiques sanguins sont nécessaires pour affirmer le diagnostic de lymphome T érythrodermique. Ces examens tendent à s'améliorer, en augmentant leur sensibilité et leur spécificité.

Un des premiers examens qui a pu être réalisé, est le frottis sanguin coloré au May-GrünwaldGiemsa, permettant la recherche des cellules dites " de Sézary », reconnaissables par leur noyau encoché, possédant une chromatine dense, parcourue de sillons en " coup d'ongles » à leur surface nucléaire. Ce noyau est dit « cérébriforme ». Leur nombre a d'abord été chiffré en pourcentage, mais c'est finalement la valeur absolue qui est à retenir. Néanmoins, ce décompte de cellules de Sézary reste subjectif avec une forte variabilité inter-opérateurs. Elle est maintenant réalisée par cytométrie de flux avec marquage immunologique. Néanmoins, ces cellules ne sont pas spécifiques des LTCE, et peuvent être identifiées chez des 
sujets sains ou atteints de pathologies dermatologiques "bénignes ", bien qu'en nombre souvent plus faible dans ce cas (4). C'est pourquoi, la valeur diagnostique retenue est un nombre de cellules de Sézary supérieur à $1000 / \mu \mathrm{L}$, qui est un critère spécifique, avec un taux de faux positifs inférieur à $10 \%$. Ce compte peut également entraîner des faux négatifs, dans environ $25 \%$ des cas (11). Un autre critère spécifique, mais peu sensible, est la présence de cellules de Sézary larges, de taille $>14 \mu m(8,12)$. Cette technique n'est donc pas idéale, du fait de la forte variabilité inter-opérateurs, mais reste facile à faire en pratique et à moindre coût (13).

La numération formule sanguine est souvent normale dans le lymphome $T$ cutané érythrodermique, mais peut être une aide au diagnostic, lorsqu'elle montre une éosinophilie. Celle-ci n'est pas spécifique des LTC, mais est retrouvée dans $20 \%$ des cas, et est associée à un moins bon pronostic, tout comme une élévation des $\operatorname{LDH}(7,9)$.

\section{Cytométrie de flux avec marquage immunologique (FACS)}

Cette technique permet de séparer les lymphocytes circulants selon l'expression de différents marqueurs membranaires :

- $\quad$ CD2 et CD3, marqueurs membranaires pan- $T$, dont l'expression peut être perdue dans les lymphomes cutanés,

- marqueurs membranaires de populations différenciées: CD4 et CD8, avec une population majoritairement CD4+ dans le cadre des LTCE. En effet, un compte de cellules CD8+ inférieur à $10 \%$ est très en faveur du diagnostic (7),

- $\quad$ CD7, CD25, CD30, CD95 qui sont des marqueurs d'activation,

- CD25, qui identifie les lymphocytes régulateurs,

- CD56 marqueur membranaire des lymphocytes NK, 
- récepteur T (TCR).

Un rapport CD4/CD8 supérieur à 10 est retrouvé chez 60 à $80 \%$ des patients avec LTCE $(4,14)$. Il est cependant peu sensible, et peut être augmenté dans des pathologies bénignes (8).

On recherche également la perte d'expression de certains antigènes pan-T $(C D 2, C D 5, C D 7$, CD26). Les cellules tumorales des LTCE présentent souvent une perte d'expression de CD7, mais elle n'est pas obligatoire. A l'inverse, $10 \%$ des cellules saines peuvent ne pas exprimer le CD7 (9). II n'a cependant pas été décrit de relation significative entre le nombre de cellules CD4+ CD7- et le nombre de cellules de Sézary (14).

L'antigène CD26 est exprimé de manière constitutionnelle par les cellules endothéliales et épithéliales de nombreux tissus, et par plus de $50 \%$ des lymphocytes circulants chez les sujets sains. Sa diminution d'expression conduit à une augmentation du " homing " cutané des cellules T (9). On retrouve une perte de son expression dans près de $100 \%$ des LTCE (15).

On retient comme critère significatif d'atteinte hématologique un pourcentage de cellules CD4+ CD26- supérieur à 30\%. Il existe une relation directe et significative entre le pourcentage de cellules CD26- et le pourcentage de cellules de Sézary. En définitive, l'analyse du nombre de cellules CD4+ CD26- est plus performante que celle des CD4+CD7-, et que le compte de cellules de Sézary pour l'évaluation de la masse tumorale, avec $96 \%$ de sensibilité et $98 \%$ de spécificité (16). Cependant, une expression mixte de CD26- et CD26+ est possible chez $10 \%$ des patients avec LTCE, ce qui pourrait sous-estimer le nombre de cellules tumorales. Mais il s'avère que ces patients ont un meilleur pronostic que ceux avec perte complète du CD26 $(14,17)$.

En 2001, un nouveau marqueur a été identifié, le CD158k/KIR3DL2, considéré comme le plus spécifique des cellules de Sézary. Chez le sujet sain, son expression est restreinte à de rares cellules NK et quelques lymphocytes T CD8+ circulants, et il n'est pas retrouvé sur les 
lymphocytes T CD4+ (18). Il appartient à la famille des KIRs (Killer-cell Immunoglobulin-like Receptor) et il est retrouvé à la surface des lymphocytes atypiques dans le sang des patients atteints de LTCE, mais pas dans d'autres dermatoses inflammatoires bénignes. Son expression est considérée significative si le nombre absolu de cellules CD158k+ est supérieur à $200 / \mu \mathrm{L}$, ou $>10 \%$ des lymphocytes en cas de lymphopénie. La valeur absolue du nombre de cellules CD3+CD158k+ est plus sensible que la valeur absolue du nombre de cellules de Sézary détectées en cytomorphologie pour évaluer la masse tumorale sanguine (19). Le transcrit CD158k/KIR3DL2 est aussi surexprimé dans les biopsies cutanées de patients atteints d'un LTCE, comparativement à des patients atteints d'autres érythrodermies inflammatoires $(18,20)$. Il serait donc utile pour le diagnostic ainsi que pour le suivi d'un patient atteint de LTCE, car son expression est corrélée au nombre de cellules de Sézary, et à la proportion de rechutes cutanées, mais son analyse est encore peu disponible en routine (18).

Une autre piste récente est l'étude du CD39, qui est impliqué dans le contrôle de la réponse immunitaire et notamment de la régulation des cellules $T$. II est surexprimé de manière significative par les cellules tumorales, et participe à la suppression de la réponse antitumorale. Des données suggèrent l'intérêt d'une recherche combinée de KIR3DL2 et CD39 pour le diagnostic (21). Il est donc difficile d'établir un diagnostic de LTCE sur un critère biologique unique.

En 2008, Klemke et al (11) ont étudié des patients diagnostiqués « Syndrome de Sézary » selon les critères ISCL, et les ont comparés à un groupe contrôle constitué de patients atteints de MF, eczéma, psoriasis ou GVH chronique. Aucun marqueur sanguin pris isolément ne permettait de faire le diagnostic de LTCE chez tous les patients. Cependant, grâce à la combinaison de plusieurs marqueurs : la cytométrie de flux avec phénotype CD4+ CD7- et 
expression diminuée du CD3, le niveau d'expression de CD158k et de la chaîne VBêta du TCR, tous ont pu être identifiés.

\section{Biologie moléculaire}

Les techniques de biologie moléculaire permettent la recherche d'un clone dominant T, c'està-dire d'une population lymphocytaire $T$ homogène, exprimant un même récepteur $T$, et nettement plus représentée que les autres populations de lymphocytes T. Cette recherche peut se faire dans le sang périphérique ou sur biopsie cutanée ou ganglionnaire. Elle est réalisée par PCR, en amplifiant des régions codant pour le TCR (récepteur à l'antigène des lymphocytes). Cette analyse est particulièrement utile dans les formes érythrodermiques, car la présence d'un clone Tidentique dans la peau et dans le sang est très en faveur du diagnostic de lymphome cutané. Un clone sanguin isolé n'a que peu de valeur (9). L'absence de population monoclonale détectée à un instant donné sur une lésion n'élimine pas obligatoirement le diagnostic. Il faut savoir réitérer les recherches en cas de doute. Le nombre significatif de faux négatifs peut retarder le diagnostic de CTCL avec une moyenne de 6 ans après le début des symptômes (22). Il faut cependant noter qu'un clone T dominant sanguin peut s'observer chez près de $15 \%$ de sujets sains au-delà d'un certain âge, et que les érythrodermies d'origine médicamenteuse peuvent comporter un clone dominant dans le sang et dans la peau (4). La PCR apporte un atout majeur à l'histologie, en augmentant la sensibilité du diagnostic, de $63 \%$ avec l'histologie seule, à $88 \%$ lorsqu'elles sont associées $(8,23)$.

Un grand avancement pour le diagnostic des lymphomes T cutanés est le séquençage à haut débit du gène TCRB, qui permet une identification des cellules T clonales avec une sensibilité et une spécificité supérieures à la PCR classique. II est aussi efficace pour différencier un LTC 
d'une pathologie inflammatoire bénigne $(24,25)$. Il permet la mise en évidence d'un clone T chez $100 \%$ des patients testés, contre $70 \%$ pour la PCR, et est particulièrement utile à un stade précoce (22).

\section{E. Etudes génétiques}

II n'existe aucun marqueur génétique caractéristique des cellules de Sézary, mais les anomalies chromosomiques sont fréquentes. Les séquençages du génome et de l'exome ont montré une prédominance d'altérations génétiques qui apparaissent dans le contrôle de la régulation du cycle cellulaire et l'activation des cellules T (26). Certains oncogènes ont une expression aberrante, dont l'étude pourrait permettre le diagnostic de LTCE, mais les techniques sont difficiles à mettre en œuvre en routine $(27,28)$.

\section{F. Diagnostic différentiel}

Une étude prospective récente, conduite par Miyashiro et Sanches (29), portant sur une cohorte de 309 patients érythrodermiques, retrouve comme étiologies les plus fréquentes : l'eczéma $(20,7 \%)$, le psoriasis $(16,8 \%)$, puis le syndrome de Sézary $(12,3 \%)$. Viennent ensuite les toxidermies (12,3\%), la dermatite atopique (8,7\%), et le MF (5,5\%). Pour $16,8 \%$ des patients, le diagnostic est resté incertain. D'autres pathologies peuvent être en cause, comme les photodermatoses (prédominance de $\mathrm{CD} 8+$ ), et les dermatophyties. Doivent également être évoquées les autres proliférations cellulaires T CD4+, avec signes cutanés secondaires, et toutes les autres lymphopathies (7). D'autre part, de nombreuses dermatoses inflammatoires peuvent simuler non seulement cliniquement le LTC, mais également histologiquement. 


\section{Stadification}

A. Actuelle

En 2007, le stade TNM évolue, et les manifestations hématologiques permettent de distinguer trois stades de lymphome T cutané érythrodermique (tableau 1) $(4,7)$ :

- $\quad$ B0 : moins de $5 \%$ de cellules atypiques dans le sang périphérique, avec présence ou non d'un clone T dominant,

- $\quad$ B1 : plus de $5 \%$ de cellules atypiques, mais $<1000 / \mu \mathrm{L}$, avec présence ou non d'un clone T dominant,

- $\quad$ B2 : présence d'un clone T dominant détecté dans le sang associé à plus de 1000 cellules de Sézary par microlitre.

\section{B. En développement}

L'EORTC conduit actuellement l'étude PROCLIPI (30) (Prospective Cutaneous Lymphoma International Prognostic Index study), débutée en 2015, ayant pour but de mettre au point un index pronostique des lymphomes T cutanés. Dans cette étude, elle utilise une stadification B0, B1 et B2 utilisant l'immunophénotypage sanguin par cytométrie de flux, plutôt que le décompte de cellules de Sézary.

Les critères sont les suivants :

- B0 : nombre de cellules CD4+CD7- ou CD4+ CD26- inférieur à 250/ $\mu \mathrm{L}$

- $\quad$ B1 : nombre de cellules CD4+ CD7- ou CD4+ CD26- compris entre 250 et 1000/ $\mu \mathrm{L}$

- $\quad$ B2 : nombre de cellules CD4+ CD7- ou CD4+CD26- supérieur ou égal à $1000 / \mu L$, ou ratio CD4/CD8 supérieur à 10 , ou plus de $40 \%$ de cellules CD4+CD7- ou plus de $30 \%$ de cellules CD4+ CD26-, et présence d'un clone T sanguin. 
Pour les stades B0 et B1, les critères a et b sont définis par l'absence (a) ou la présence (b) d'un clone T sanguin majoritaire (31). Cette classification a été utilisée dans notre étude pour analyser la survie des patients avec LTCE.

\section{Traitements et survie}

Le lymphome T cutané érythrodermique étant une maladie rare, la mise en place d'études cliniques de grande envergure est difficile, c'est pourquoi peu de données sont disponibles concernant la survie sous traitement. Le choix du traitement est basé sur l'extension clinique de la maladie, le terrain du patient, et l'impact potentiel sur la qualité de vie. Les approches actuelles sont les biothérapies, les thérapies ciblées et les immunothérapies, qui fournissent un traitement sur le long-terme, avec un minimum d'effets secondaires et de retentissement sur la vie du patient. Néanmoins, aucune de ces approches n'est curative. L'exception est l'allogreffe de moelle, qui entraîne des réponses complètes et durables chez la majorité des patients $(7,24)$.

\section{A. Traitements locaux}

Les traitements locaux comme les dermocorticoïdes, les rétinoïdes locaux, les gels de méchloretamine ou la PUVA sont associés à une réponse allant de 50 à $100 \%$. Ils peuvent être associés à des thérapies systémiques pour une meilleure réponse (24). 
B. Traitements modificateurs de la réponse immune

Ils représentent la première ligne de traitement, et peuvent parfois être associés entre eux. La photophérèse extracorporelle est bien tolérée avec peu d'effets secondaires, et offre environ 56\% de réponses chez les LTCE, avec une médiane de survie de plus de 8 ans $(32,33)$. Le bexarotène oral (TARGRETIN), est un rétinoïde synthétique, qui, chez les patients à un stade avancé, permet une réponse variant de $36 \%$ à $45 \%$ dont $13 \%$ de réponses complètes. Ses effets secondaires les plus notables sont l'hypertriglycéridémie et l'hypothyroïdie, toutes deux réversibles à l'arrêt du traitement (32).

L'interféron alpha est une cytokine endogène, dont l'efficacité est dose dépendante, avec une réponse de 50 à $78 \%$ à haute dose, dont $27 \%$ de réponses complètes. La durée de réponse moyenne est de 14 semaines. II peut engendrer des effets secondaires aigus et chroniques, nécessitant une surveillance rapprochée (32). II n'est malheureusement plus commercialisé depuis l'été 2020.

Le Vorinostat est un inhibiteur de I'HDAC (histone dé-acétylase), engendrant 33,3\% de réponses chez les patients avec LTCE, pour une durée de réponse médiane de 185 jours $(32,33)$

\section{Chimiothérapies systémiques}

Ces traitements sont initiés en $2^{\mathrm{e}}$ ligne, avec des molécules variées (doxorubicine, gemcitabine, chlorambucil, etoposide, cyclophosphamide, méthotrexate haute dose) qui peuvent être associées. Leur réponse est rarement durable, et plus de $90 \%$ des patients qui reçoivent ces traitements devront recevoir une thérapie additionnelle pendant la $1^{\text {ère }}$ année 
de traitement. De plus, une première ligne de traitement par chimiothérapie est associée à une augmentation de la mortalité (33).

\section{Immunothérapies}

Ces traitements sont les plus utilisés en $2^{\mathrm{e}}$ ligne.

Le Mogamulizumab, est un anticorps sélectif du CCR-4, qui agit en diminuant l'activité T régulatrice et en inhibant le homing cutané des lymphocytes. C'est un traitement récent, approuvé aux Etats-Unis depuis septembre 2018 seulement. II a montré une réponse de 37\% chez les patients atteints de LTCE, avec une durée de réponse médiane de 25,5 mois (32).

L'Alemtuzumab, est un anticorps monoclonal dirigé contre le CD52 offrant des réponses allant de 51 à 84\%, qui sont meilleures chez les patients érythrodermiques. Pour la plupart des patients, il permet plus de 12 mois sans rechute de la maladie $(32,33)$. II n'a plus l'AMM pour le traitement des lymphomes T cutanés.

\section{E. Allogreffe de de cellules souches}

C'est le seul traitement potentiellement curatif à l'heure actuelle, avec $90 \%$ de réponses. La survie globale des patients traités est de $76 \%$ à 2 ans et $46 \%$ à 5 ans. La survie sans progression est de $50 \%$ à 2 ans et de $34 \%$ à 10 ans. Son principal effet secondaire est la réaction du greffon contre l'hôte, qui survient en phase aigüe chez $23 \%$ des patients, et devient chronique chez $23 \%$ d'entre eux $(24,32)$. Elle reste un traitement lourd, qui ne peut être réalisé presque exclusivement que chez des patients jeunes et en bonne santé, à un stade avancé de la maladie (7). 


\section{F. Traitements en cours de développement}

L'anti-KIR3DL2 a montré une efficacité dans les modèles précliniques, avec des résultats encourageants montrant $42,9 \%$ de réponses chez les patients érythrodermiques (32). Un essai clinique de phase II est en cours.

D'autres cibles thérapeutiques sont en développement, comme le CD3, le CD25 (récepteur de I'IL-2), et le récepteur au PD-1 (7).

\section{Eléments pronostiques}

\section{A. Etudes de survie}

Peu d'études de survie ont été réalisées chez les patients avec LTCE uniquement, et la majorité s'intéressent au pronostic global des lymphomes T cutanés épidermotropes, y compris le MF. L'étude des survies spécifique et globale des lymphomes T cutanés est difficile, car il n'est pas toujours évident de déterminer si le décès est dû ou non à la maladie. On sait que ces patients sont à risque élevé de sepsis, du fait d'une altération de la fonction barrière de la peau, et d'une mauvaise thermorégulation. Donc, si un patient décède des suites d'une infection, d'un arrêt cardiaque, d'un cancer secondaire, ou d'une autre cause non directement liée au lymphome cutané, la décision de l'imputabilité du lymphome devient arbitraire, exception faite d'un lymphome en rémission complète au moment du décès. C'est pour cela que certains auteurs considèrent que le pronostic des différents stades B devrait être étudié sur la survie globale et non la survie spécifique (13). Dans la littérature, la survie des patients atteints de LTC est étudiée selon le stade TNM (tableau 1). Or, dans cette classification, les patients érythrodermiques peuvent être classés dans plusieurs stades. En effet, le stade III ne 
comprend que des patients érythrodermiques, avec atteinte sanguine ou non (B0 ou B1), et le stade IV correspond aux patients avec atteinte sanguine B2, ganglionnaire ou viscérale, quelle que soit l'atteinte cutanée (34).

En 1997 la survie à 5 ans des « syndrome de Sézary " selon la classification EORTC publiée par Willemze et al (35), était de 11\%. Les auteurs ont étudié une cohorte de 626 patients atteints de lymphome T cutané, dont 12 diagnostiqués SS, et suivis de 1986 à 1994. Leur survie médiane était inférieure à 3 ans.

En 1998, une nouvelle étude, sur une cohorte de 62 patients atteints de syndrome de Sézary, est conduite par Bernengo et al (36). Les critères d'inclusion étaient une érythrodermie avec adénomégalies périphériques, des cellules de Sézary circulantes $>1000 / \mu \mathrm{L}$ ou $>10 \%$ des leucocytes, et une histologie de CTCL. Les patients avec MF ayant développé une érythrodermie et une atteinte sanguine étaient également inclus. La survie globale médiane des patients était de 31 mois, avec une survie globale à 5 ans de 33,5\%.

En 2001, Scarisbrick et al (37) proposent une étude de survie selon une nouvelle stadification sanguine $\mathrm{H}$, intégrant la présence ou non d'un clone cellulaire retrouvé par PCR (tableau 3). Elle semblait avoir une bonne valeur pronostique, puisqu'elle montrait des différences significatives de mortalité spécifique entre les stades. Cette étude portait sur une cohorte de 57 patients érythrodermiques, y compris des MF. Cependant, les données de survie globale des patients n'étaient pas renseignées. 
Tableau 3 : Stadification $\mathrm{H}$ de l'atteinte sanguine

Scarisbrick JJ, Whittaker S, Evans AV, Fraser-Andrews EA, Child FJ, Dean A, et al. Prognostic significance of tumor burden in the blood of patients with erythrodermic primary cutaneous T-cell lymphoma. Blood. 1 févr 2001;97(3):624-30

\begin{tabular}{|l|l|l|l|l|}
\hline Stade sanguin & $\begin{array}{l}\text { Analyse du TCR } \\
\text { par PCR }\end{array}$ & $\begin{array}{l}\text { Analyse du TCR } \\
\text { par Southern } \\
\text { blot }\end{array}$ & $\begin{array}{l}\text { Cellules dézary en \% } \\
\text { Ser }\end{array}$ & $\begin{array}{l}\text { Compte absolu } \\
\text { de cellules de } \\
\text { Sézary x 10^9/L }\end{array}$ \\
\hline $\mathrm{H} 0$ & Polyclonal & Polyclonal & 0 & 0 \\
\hline $\mathrm{H} 1$ & Clonal & Polyclonal & $<5$ & 0 \\
\hline $\mathrm{H} 2$ & Clonal & Clonal & $>5$ & $<1$ \\
\hline $\mathrm{H} 3$ & Clonal & Clonal & $>5$ & $1-10$ \\
\hline $\mathrm{H} 4$ & Clonal & Clonal & $>5$ & $>10$ \\
\hline
\end{tabular}

La mortalité spécifique des stades H2 (équivalent B1 pour l'ISCL) était 5 fois plus importante que celle des stades $\mathrm{HO}$ et $\mathrm{H} 1$ (équivalents $\mathrm{BO}$ ) confondus. Le stade $\mathrm{H} 3$ (équivalent B2 pour I'ISCL) avait un taux de mortalité 3,5 fois plus important que l'ensemble des patients classés de $\mathrm{HO}$ à $\mathrm{H} 2$. Et le stade $\mathrm{H} 4$ avait le moins bon pronostic, avec un taux de mortalité 2,5 fois plus élevé que les patients classés de H0 à H3. Néanmoins, il n’y avait pas de différence de mortalité significative entre les patients $\mathrm{H} 2$ et $\mathrm{H} 3, \mathrm{H} 2$ et $\mathrm{H} 4$, et $\mathrm{H} 3$ et $\mathrm{H} 4$.

En 2009, Vidulich et al (38) ont étudié rétrospectivement 124 patients classés LTCE, avec comme critères d'inclusion l'érythrodermie, et une histologie montrant un épidermotropisme, un infiltrat lymphocytaire atypique, ou un infiltrat périvasculaire non spécifique. Les patients avec MF érythrodermique étaient également inclus. La médiane de survie pour les LTCE était de 5,1 ans, avec une survie à 5 et 10 ans de $51 \%$ et $29 \%$ respectivement. Ils ont également comparé les valeurs pronostiques de différentes classifications sanguines: la classification anglaise $\mathrm{H}$, la classification de l'ISCL et la classification révisée par Vonderheid et al (tableau 4). Aucune différence de survie 
significative n'était retrouvée entre les patients lorsqu'ils étaient classés par les stades de I’ISCL et de Vonderheid et al. Seule la stadification H (déjà étudiée par Scarisbrick et al en 2001) montrait une différence de survie significative entre les stades $\mathrm{HO}-\mathrm{H} 2$, et les stades $\mathrm{H} 3$ et $\mathrm{H} 4$.

Tableau 4 : Propositions de stadification sanguine des lymphomes T cutanés érythrodermiques

Vidulich KA, Talpur R, Bassett RL, Duvic M. Overall survival in erythrodermic cutaneous T-cell lymphoma: an analysis of prognostic factors in a cohort of patients with erythrodermic cutaneous $T$ cell lymphoma. Int J Dermatol. mars 2009;48(3):243-52.

\begin{tabular}{|c|c|c|}
\hline Classification $\mathrm{H}$ & Classification ISCL & Classification de Vonderheid \\
\hline HO : pas de clone & B0 : MF érythrodermique & $\begin{array}{l}\mathrm{B} 0<1000 / \mu \mathrm{L} \text { cellules de } \\
\text { Sézary }\end{array}$ \\
\hline \multicolumn{3}{|l|}{ H1 : clone par PCR } \\
\hline $\begin{array}{l}\mathrm{H} 2>5 \% \text { cellules de Sézary }+ \\
\text { clone }\end{array}$ & $\begin{array}{l}>5 \% \text { cellules de Sézary }+ \\
\text { clone }\end{array}$ & \\
\hline $\begin{array}{l}\mathrm{H} 3>1000 / \mu \mathrm{L} \text { cellules de } \\
\text { Sézary }\end{array}$ & $\begin{array}{l}\text { B2 > } 1000 \text { cellules de Sézary } \\
\text { ou clone }\end{array}$ & $\begin{array}{l}\text { B1 > 1000/ } \mu \mathrm{L} \text { cellules de } \\
\text { Sézary }\end{array}$ \\
\hline $\begin{array}{l}\text { H4 }>10000 / \mu \mathrm{L} \text { cellules de } \\
\text { Sézary }\end{array}$ & & 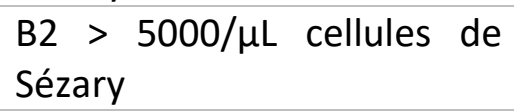 \\
\hline
\end{tabular}

En 2010, Agar et al (39) ont étudié une cohorte de 1502 patients atteints de lymphome T cutané type MF ou syndrome de Sézary. Chez les patients érythrodermiques, la survie médiane était de 3,9 ans, avec une survie globale à 5, 10 et 20 ans de $41 \%, 27 \%$ et $18 \%$ et une survie spécifique de $48 \%$, 35\% et $26 \%$ respectivement. La survie a aussi été étudiée selon le stade sanguin B sur 175 patients, y compris des patients non érythrodermiques. Une différence significative de survie globale et spécifique a été montrée entre les stades B0a et B0b, (soit la présence ou non d'un clone cellulaire T dans le sang) mais paradoxalement, pas entre les stades B1a et B1b. Une différence significative a également été retrouvée entre B1 et B2. On notait une survie globale à 5 ans de $76 \%$ pour tous les stades $\mathrm{B} 0$, (87\% pour B0a, $63 \%$ pour $\mathrm{B} 0 \mathrm{~b})$, de $34 \%$ pour les stades $\mathrm{B} 1$, et de $26 \%$ pour $\mathrm{B} 2$. La survie spécifique à 5 ans était un peu plus élevée, soit de $82 \%, 40 \%$ et $31 \%$ respectivement. 
Les auteurs ont également étudié la survie des patients selon le stade clinique initial. La mortalité était significativement moins élevée pour les stades IIIA (érythrodermie et B0) que pour les stades IIIB (érythrodermie et B1).

En 2012, Kubica et al (40) ont étudié de manière rétrospective, 176 patients avec érythrodermie et atteinte sanguine significative (cellules de Sézary circulantes $>1000 / \mu \mathrm{L}$ ou clonalité T sanguine). La survie globale était de $86,1 \%$ à 1 an, $42,3 \%$ à 5 ans et la survie médiane de 4 ans.

Une étude de cohorte de 2012, réalisée par Talpur et al (41) sur 1263 patients atteints de lymphome T cutané type MF ou syndrome de Sézary, retrouvait une survie médiane des patients T4 (érythrodermiques) de 5 ans. La survie globale à 5, 10 et 20 ans était de $52 \%, 29 \%$ et $12 \%$ respectivement. L'étude de survie selon l'atteinte sanguine $B$, considérant $B 0$ comme un compte de cellules de Sézary $<500 / \mu \mathrm{L}$, B1 entre 500 et $1000 / \mu \mathrm{L}$, et B2 $>1000 / \mu \mathrm{L}$ ou $>35 \%$ de lymphocytes CD7- ou CD26-, montrait une différence significative de survies globale et spécifique entre les stades B0 et B2. La survie médiane des patients B2 était de 4,62 ans, comparée à 29,28 ans pour les patients B0. L'étude des patients B1 était limitée par un effectif trop réduit.

En 2015, Scarisbrick et al (42) ont conduit une nouvelle étude de survie, rétrospective et multicentrique, incluant une cohorte de 1275 patients avec un stade avancé de MF ou de lymphome T érythrodermique. L'étude sur le stade clinique initial montrait une survie globale à 5 ans de $58,2 \%$ pour les stades III (érythrodermiques B0 ou B1), mais ce chiffre ne comprenait pas les données des patients B2. Les courbes de survie comparant les stades B0, B1 et B2 ne montraient une différence significative de survie globale qu'entre B0 et B2. 
La même année, Klemke et al (10) ont étudié la survie de 57 patients diagnostiqués " syndrome de Sézary » (érythrodermiques avec cellules de Sézary circulantes supérieures à $1000 / \mu \mathrm{L}$, un rapport CD4/CD8 supérieur à 10 , ou un réarrangement monoclonal du gène du TCR) en excluant les MF érythrodermiques. La survie médiane était de 61 mois, avec une survie globale à 5 ans de $51,4 \%$.

En 2017, Mangold et al (5) ont colligé 263 patients atteints de "syndrome de Sézary », et retrouvaient une survie médiane de 4,4 ans. Les critères d'inclusion étaient une érythrodermie, associée à au moins 2 critères parmi les suivants : cellules de Sézary $>1000 / \mu L$, CD4/CD8 >10, perte de marqueurs pan- $T$ (CD2, CD3, CD4, CD5, CD7 ou CD26), la présence d'un clone T monoclonal, ou la présence d'un clone T cellulaire avec anomalie chromosomique.

Dans la dernière classification EORTC 2018 de Willemze et al (27), basée sur une cohorte néerlandaise et autrichienne, la survie spécifique des patients considérés « syndrome de Sézary » (érythrodermiques, avec des cellules de Sézary circulantes supérieures à 1000/ $\mu$ L, un rapport $C D 4 / C D 8>10$, un compte de cellules $C D 4+C D 7$ - supérieur à $30 \%$, ou des cellules CD4+ CD26- >40\%) était de $36 \%$ à 5 ans.

Ces chiffres montrent l'importante disparité des données de survie des lymphomes T érythrodermiques.

A noter, que lors de leur étude en 2016, comparant les MF érythrodermiques et les "syndromes de Sézary ", Hurabielle et al (43) ont remarqué que certains patients B1 évoluaient vers un stade B2, mais qu'aucun patient B0 n'évoluait vers le stade B2 (sur une durée de suivi médiane de 1,6 ans). 
Tableau 5 : Comparatif des différentes études de survie au cours des années

OS = overall survival (survie globale)

DSS = disease specific survical (survie spécifique)

$N R$ : Non renseigné

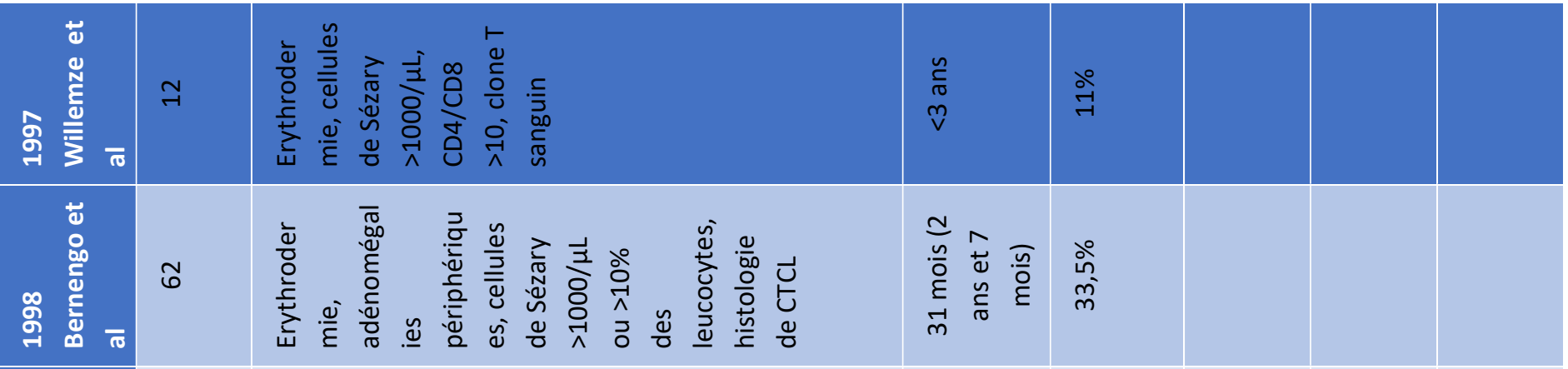

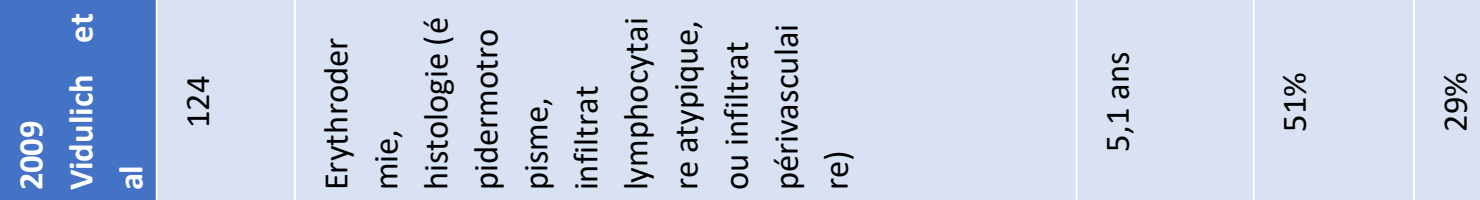

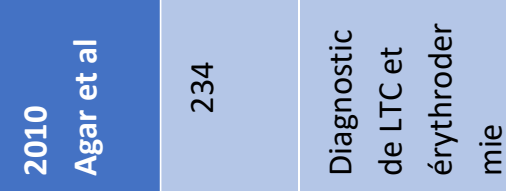

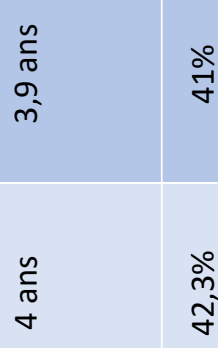

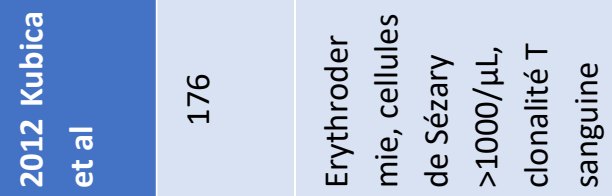

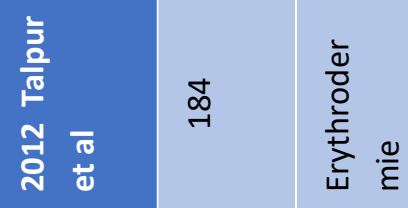

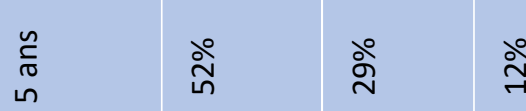

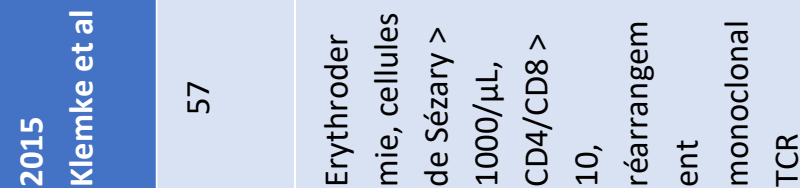

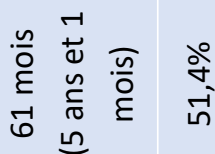

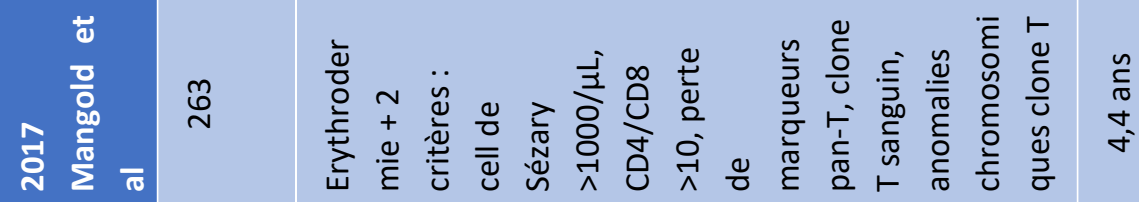

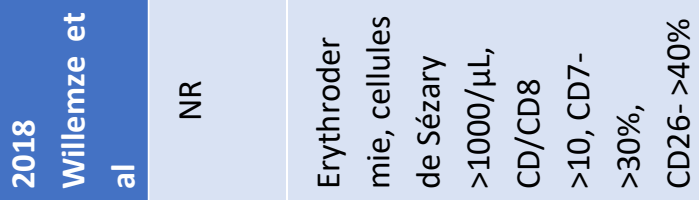

$+$

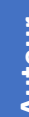

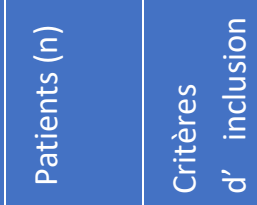

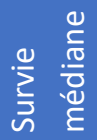

$\tilde{0} \frac{n}{n}$

صू

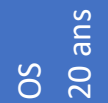

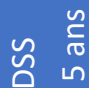




\section{B. Marqueurs pronostiques}

Au cours des dernières années, différentes études ont été menées pour identifier des marqueurs pronostiques de la maladie, qu'ils soient cliniques, histologiques ou biologiques. L'érythrodermie en elle-même semble être un facteur de mauvais pronostic, car ces patients sont à risque plus élevé de sepsis, et de troubles de thermorégulation. Ils ont également un trouble de l'immunité, qui les rend vulnérables aux infections et au développement d'autres pathologies tumorales (38).

Les marqueurs de mauvais pronostic les plus fréquents sont l'âge avancé (supérieur à 60 ans), le sexe masculin, l'élévation des $\operatorname{LDH}$ dans le sang, et l'éosinophilie sanguine $(3,34,38)$. Diamandidou et al (45) ont montré que la présence d'au moins un de ces facteurs est corrélée à une médiane de survie entre 2,5 et 3,5 ans, comparée à une survie supérieure à 13 ans pour les patients sans ces paramètres.

\section{Marqueurs cliniques}

Le mauvais pronostic de l'âge avancé (>60 ans) a longtemps été débattu, afin de savoir s'il était un facteur pronostique indépendant ou si les patients âgés avaient une tendance à présenter un stade plus avancé de la maladie. L'association entre survie globale et âge avancé a été démontrée dans de nombreuses études, mais très peu sont parvenues à montrer une association significative avec la survie spécifique (46).

\section{Marqueurs histologiques}

En 2019, Vonderheid et al (47) ont comparé les histologies de deux groupes de patients : ceux avec lymphome T érythrodermique et cellules de Sézary/ $\mu L>1000$, et les patients ayant une érythrodermie sans critère hématologique. Ils ont mis en évidence comme facteur de mauvais 
pronostic un taux de cellules CD8+ inférieur à $20 \%$ des lymphocytes de l'infiltrat. L'absence d'abcès de Pautrier semblait de moins bon pronostic chez les patients avec une atteinte hématologique, et s'ils étaient présents, alors leur grande taille était de moins bon pronostic. La présence d'un infiltrat à éosinophiles était de meilleur pronostic, contrairement à l'éosinophilie sanguine.

\section{Marqueurs biologiques}

Une étude anglaise de 2013 réalisée par Benton et al (48), sur 1502 patients atteints de MF ou de LTCE, retrouvait comme facteurs de mauvais pronostic le stade ganglionnaire N2/N3, les stades sanguins B1 et B2, ainsi que l'atteinte viscérale.

La clonalité T sanguine est également déterminante pour le pronostic, comme l’ont montré Beylot-Barry et al (23) dans leur étude de 2001, incluant 85 patients avec lymphome T cutané primitif. Lorsqu'un clone cellulaire T était retrouvé seulement dans la peau, il n'avait pas d'incidence sur la progression de la maladie, alors qu'une identité clonale entre la peau et le sang périphérique montrait un risque significatif de progression de la maladie.

Concernant la cytométrie de flux, la perte partielle ou totale d'expression de CD7 ou CD26 par les lymphocytes T CD4+ circulants est de mauvais pronostic. Vonderheid et Bernengo (49) ont utilisé le nombre absolu de cellules CD4+ CD26- pour identifier deux groupes de patients (nombre inférieur ou supérieur à 2000 cellules/ $\mu \mathrm{L}$ ) aux pronostics significativement différents, parmi 75 patients atteints de LTCE avec cellules de Sézary circulantes. Les patients avec des lymphocytes CD7+ avaient une survie globale significativement plus élevée que ceux avec perte d'expression ( $47 \%$ et $18 \%$ respectivement à 5 ans). 
A ce jour, le KIR3DL2 est le meilleur facteur pronostique indépendant pour les LTCE, avec une survie globale réduite en cas de cellules KIR3DL2+ supérieures à $85 \%$ des lymphocytes circulants $\mathrm{CD} 3+$, ou plus de $10 \%$ des lymphocytes cutanés. Il apparait également être un marqueur intéressant et précoce de la réduction de la charge tumorale, et du risque de rechute $(20,50)$.

La T-plastine est une protéine cytoplasmique, exprimée de manière aberrante par les cellules de Sézary, qui jouerait un rôle dans la migration cellulaire. Les cellules tumorales expriment le gène codant pour la T-plastine environ 20 fois plus que les cellules T-helper de patients sains ou atteints d'autres dermatoses inflammatoires. Son ARN peut être détecté par RT-PCR sur le sang périphérique, et est retrouvé chez environ $78 \%$ des patients avec un syndrome de Sézary. Son rôle pathogénique dans le développement des cellules de Sézary n'est pas encore élucidé, mais elle semble leur conférer une résistance à l'apoptose médicamenteuse (51). Son expression serait corrélée à l'importance de la charge tumorale sanguine, et elle peut donc représenter un marqueur potentiel pour le diagnostic et le suivi des patients (52). II a également été montré que les patients surexprimant le gène de la T-plastine semblent avoir un meilleur pronostic (53).

Tous ces marqueurs pronostiques sont difficiles à évaluer de manière indépendante, car selon les études, leur corrélation avec la survie n'est pas toujours significative. C'est pourquoi sont développés des index pronostiques (comme le PROCLIPI), qui associent plusieurs de ces marqueurs afin de classer les patients en différents groupes pronostiques, comme cela est déjà fait pour certains lymphomes ganglionnaires ou systémiques $(42,48)$. 


\section{PARTIE}

EXPERIMENTALE 


\section{Pronostic des lymphomes T érythrodermiques}

Mots-clés : lymphome $\mathrm{T}$ cutané érythrodermique, pronostic, classification sanguine, syndrome de Sézary, survie globale

\section{Résumé}

Introduction : les lymphomes T cutanés érythrodermiques (LTCE), sont classés en stades B0, B1 ou B2 selon l'importance de leur charge tumorale sanguine initiale. Leur pronostic est diversement apprécié selon les études, mais il tend à s'améliorer ces dernières années, notamment pour les patients B2. Ces stades sont souvent envisagés comme un spectre évolutif, mais peu d'études ont évalué le risque de passage d'un stade à l'autre.

Matériel et méthodes : tous les patients suivis au CHU de Clermont-Ferrand entre 2000 et 2018 présentant une érythrodermie et une histologie cutanée compatible avec un lymphome $\mathrm{T}$ cutané épidermotrope ont été inclus. Ils ont été, rétrospectivement classés B0 («mycosis fongoïde érythrodermique »), B1 («pré-Sézary ») ou B2 («maladie de Sézary ») selon les critères PROCLIPI (1). La survie (globale et spécifique) de la population entière et de chaque groupe a été estimée par la méthode de Kaplan-Meier, depuis la date du diagnostic jusqu'au décès, ou jusqu'à la date des dernières nouvelles.

Résultats : cinquante-deux patients ont été inclus, dont 26 classés B0, 11 classés B1 et 15 classés B2. La durée médiane de suivi était de 35,5 mois [20,75-55,25]. La survie globale à 5 ans tous stades confondus était de $57,5 \%$, et la survie spécifique à 5 ans de $75,6 \%$. La survie globale à 5 ans des patients B2 était de $48 \%$. Il n'a pas été retrouvé de différence significative de survie globale selon le stade B initial. Quatre patients ont changé de stade B au cours du suivi, 2 sont passés de $\mathrm{B} 0$ à $\mathrm{B} 1$ et 2 de $\mathrm{B} 1$ à $\mathrm{B} 2$.

Conclusion : la survie globale des LTCE, et notamment des stades B2, semble s'améliorer au cours des années, selon les différentes études de survie, ce qui est probablement expliqué par l'utilisation de nouveaux traitements, plus performants. Notre étude confirme cette tendance, avec une survie globale à 5 ans de $57,5 \%$ tous stades confondus, et de $48 \%$ pour les stades B2, alors qu'elle était estimée à 11\% en 1997 (2). D'autre part, la gradation en stades B ne semble pas représenter un continuum au cours de l'évolution des LTCE, car seuls 7,7\% de nos patients sont passés d'un stade à un autre, sur une durée médiane de suivi de 35,5 mois. 


\section{Introduction}

Les lymphomes cutanés représentent la localisation la plus fréquente des lymphomes extraganglionnaires, avec 75\% de lymphomes T. Le lymphome T cutané érythrodermique (LTCE) est une entité bien définie dans la classification EORTC, et se présente cliniquement sous la forme d'une érythrodermie (érythème de la quasi-totalité du corps évoluant sur plusieurs semaines) (3). Les patients avec LTCE sont classés en trois groupes B0, B1 et B2 selon l'importance de la charge tumorale circulante, le groupe B0 correspondant au «MF érythrodermique », le groupe B2 au «syndrome de Sézary», et le groupe B1 à un stade intermédiaire.

Leur pronostic est varié, et plusieurs auteurs ont tenté de déterminer des facteurs ou des combinaisons de facteurs pronostiques (cliniques, cytologiques ou moléculaires) permettant de prédire leur survie (4). Cependant, très peu d'études ont spécifiquement analysé la valeur pronostique de la classification B, pourtant utilisée quotidiennement par le clinicien. En effet, la plupart des études analysent la survie des seuls patients B2 («syndromes de Sézary »), en excluant les patients érythrodermiques sans atteinte sanguine (B0), ou avec atteinte intermédiaire (B1).

Dans notre étude rétrospective monocentrique, nous avons étudié la survie (globale et spécifique) des patients avec lymphome T cutané érythrodermique, et l'impact sur la survie de différents marqueurs cliniques, histologiques et biologiques, et notamment le stade B lors du diagnostic initial.

\section{Matériel et méthodes}

Nous avons inclus de manière rétrospective tous les patients ayant été suivis dans le service de Dermatologie du CHU Estaing entre 2000 et 2018, et dont le code diagnostic CIM-10 retenu dans notre base de données était « syndrome de Sézary » (code C841). Les patients ont été exclus en cas de données incomplètes, de diagnostic incertain, ou si une autre étiologie d'érythrodermie a été mise en évidence.

Les données suivantes ont été recueillies de manière rétrospective, à la date du diagnostic : le sexe, l'âge, le nombre absolu de cellules de Sézary, le rapport CD4/CD8, la présence d'un clone cellulaire $\mathrm{T}$ cutané et sanguin, ainsi que la présence d'une identité clonale sang/peau, le nombre de lymphocytes atypiques (CD4+CD7- et/ou CD4+CD26-) recueilli par immunophénotypage, la perte d'expression de CD7 ou CD26, et l'expression de CD158k. L'année de la première biopsie évocatrice a été retenue comme date du diagnostic. Le nombre de cellules de Sézary a été recueilli par décompte sur frottis sanguin. Le rapport CD4/CD8 a été calculé sur les résultats de l'immunophénotypage sanguin, et considéré positif si supérieur à 10. La présence d'un clone cellulaire $\mathrm{T}$ dans la biopsie cutanée ou dans le sang périphérique a été recherchée par PCR. Les stades B0, B1 et B2 ont été déterminés selon la classification PROCLIPI (Tableau 1) (1) pour 37 patients, et les 15 autres patients ont été classés selon l'ISCL (Tableau 2) (5) sur le nombre absolu de cellules de Sézary, par manque de données de l'immunophénotypage.

Les patients ont été divisés en 3 groupes, selon leur stade sanguin B0, B1 ou B2. Le critère de jugement principal était la moyenne de survie globale des patients en années, calculée depuis 
la date de diagnostic, jusqu'au décès toutes causes confondues, ou à la date des dernières nouvelles.

Les analyses statistiques ont été réalisées avec le logiciel Stata (version 15, StataCorp, College Station, Texas, USA), en considérant un risque d'erreur de première espèce bilatéral de $5 \%$. La population est décrite par des effectifs et pourcentages associés pour les variables catégorielles et par la moyenne \pm écart-type ou la médiane [intervalle interquartile] pour les variables quantitatives, au regard de leur distribution statistique. La normalité a été étudiée par le test de Shapiro-Wilk et/ou par histogramme. Les données censurées (survie globale et survie spécifique) ont été estimées par la méthode de Kaplan-Meier. La statistique du log-rank a été utilisée en analyse univariée afin d'étudier les relations entre les caractéristiques des patients et leur survie à 5 ans. Des régressions de Cox ont dans un second temps été considérées afin de tenir compte d'un ajustement sur l'âge. Les résultats sont exprimés sous forme d'hazard ratios et intervalles de confiance (IC) à $95 \%$. Un $\mathrm{p}<0.05$ était retenu comme statistiquement significatif.

\section{Résultats}

Après avoir interrogé notre base de données, un total de 81 patients codés C841 ou « syndrome de Sézary » étaient éligibles au sein de l'étude. Les dossiers ont été revus, et 29 patients ont été exclus, dont 11 pour diagnostic non confirmé, 7 patients non érythrodermiques au diagnostic (code inadéquat), 5 patients avec une autre étiologie d'érythrodermie inflammatoire ( 3 eczémas, 1 parapsoriasis et 1 toxidermie), 3 patients avec une autre lymphopathie érythrodermique (1 lymphome B, 1 lymphome plasmablastique, 1 lymphome pilotrope), et 3 patients exclus par manque de données (Fig. 1).

Un total de 52 patients, dont 22 femmes $(42,3 \%)$ et 30 hommes $(57,7 \%)$ répondaient aux critères d'inclusion. La moyenne d'âge était de 72 ans (41-92). Le suivi médian des patients était de 35,5 mois $[20,75-55,25]$.

Parmi ces 52 patients, 26 (50\%) ont été classés B0, 11 (21,1\%) classés B1 et 15 (28,8\%) classés B2, soit par la classification PROCLIPI, soit par la classification de 1'ISCL. (Fig. 2) Parmi les patients classés B0, 50\% (13 patients) étaient B0a, et 50\% B0b. Parmi les patients classés B1, $18,2 \%$ (2 patients) étaient B1a, et 81,8\% (9 patients) étaient B1b. La moyenne du compte des cellules de Sézary était de $348 / \mu \mathrm{L}$.

Le rapport CD4/CD8 moyen était de 5,1, avec 30\% des patients ayant un ratio supérieur ou égal à 10. L'étude par PCR retrouvait un clone $\mathrm{T}$ cellulaire dominant dans la biopsie cutanée de $71,4 \%$ des patients, et dans le sang périphérique de $70 \%$ des patients. Ces deux clones étaient identiques dans la peau et le sang pour $43,2 \%$ des patients. Le nombre moyen de lymphocytes atypiques (CD4+ CD7- et/ou CD26-) retrouvés à l'immunophénotypage était de $125 / \mu \mathrm{L}$, avec un immunophénotypage considéré positif (lymphocytes atypiques $>250 / \mu \mathrm{L}$ ) chez $50 \%$ des patients. Concernant le phénotype des cellules atypiques, $83,3 \%$ montraient une perte d'expression du CD26, 78,8\% du CD7, et 50\% exprimaient le CD158k. (Tableau 3) 
A la date des dernières nouvelles, 23 patients sur 52, soit 44,2\% étaient décédés, toutes causes confondues. La survie globale à 5 ans était de 57,5\% (intervalle de confiance à $95 \%: 39,1$ à $72,2 \%$ ). L'étude des différents facteurs recueillis n'a pas retrouvé de corrélation significative avec la survie globale des patients. Il n'a notamment pas été retrouvé de différence pronostique significative entre les différents stades B d'atteinte sanguine initiale. L'âge, le genre masculin, le compte des cellules de Sézary, le ratio CD4/CD8, les clonalités sanguines et cutanées, l'identité clonale peau/sang, l'immunophénotypage sanguin et la perte d'expression de CD7, ne montraient pas d'impact significatif sur la survie des patients.

L'ajustement des données sur l'âge ne retrouvait pas de différence significative, notamment entre les stades B0, B1 et B2. (Tableau 4) (Figures 3 et 4)

Sur les 23 patients décédés, la cause du décès était connue pour 12 d'entre eux (6 imputables au lymphome et 6 non imputables au lymphome) et inconnue pour les 11 autres. Si on considérait l'échantillon de $n=41$ patients ( 29 non décédés et 12 décédés de cause connue), le taux de survie spécifique à 5 ans était de 75,6\% (intervalle de confiance à 95\%: 49,6 à 89,4\%). (Figure 5) $\mathrm{Si}$ on considère que les 11 décès de cause inconnue étaient non imputables au lymphome, le taux de survie spécifique à 5 ans était de $80 \%$ (intervalle de confiance à $95 \%$ : 57,2 à 91,5\%), et si on considère qu'ils étaient imputables au lymphome, le taux de survie spécifique à 5 ans était de 61,3\% (intervalle de confiance à $95 \%: 41,7$ à $76 \%$ ). Ainsi, le véritable taux de survie spécifique à 5 ans était compris entre $61,3 \%$ et $80 \%$.

Des courbes de Kaplan-Meier ont été réalisées pour la survie spécifique de chaque stade B, mais la différence de survie entre les stades n'a pas pu être étudiée. Dans le groupe B0, parmi les causes connues de décès, aucune n'était imputable au lymphome, dans le groupe B1, tous les décès (2) étaient imputables au lymphome, et dans le groupe B2, 4 décès sur 5 étaient imputables au lymphome. Ainsi, la survie spécifique à 5 ans des stades B0 (sur les patients dont la cause du décès était connue), était de 100\%, et celle des stades B1 et B2 étaient très proches, de presque $50 \%$. (Figure 6 )

La durée de suivi médiane des patients était de 35,5 mois [20,75-55,25], et durant cette période, 6 patients $(11,5 \%)$ ont changé de stade $\mathrm{B}$. 1 patient est passé de $\mathrm{B} 0 \mathrm{a}$ à $\mathrm{B} 0 \mathrm{~b}, 1$ patient de $\mathrm{B} 1 \mathrm{a}$ à $\mathrm{B} 1 \mathrm{~b}, 2$ patients de $\mathrm{B} 0 \mathrm{~b}$ à $\mathrm{B} 1 \mathrm{~b}$, et 2 patients de $\mathrm{B} 1 \mathrm{~b}$ à $\mathrm{B} 2$. Si on considère les stades $\mathrm{B} 0, \mathrm{~B} 1$ et $\mathrm{B} 2$ (sans distinction de « $\mathrm{a} »$ et $« \mathrm{~b} »$ ), alors seuls 4 patients ont évolué : 2 sont passés de B0 à $\mathrm{B} 1$ et 2 de $\mathrm{B} 1$ à B2. (Tableau 5).

\section{Discussion}

La survie globale des LTCE, et notamment des stades B2, semble s'améliorer au cours des années, selon les différentes études de survie, ce qui est probablement expliqué par l'utilisation de nouveaux traitements, plus performants. Notre étude confirme cette tendance, avec une survie globale à 5 ans de $57,5 \%$ tous stades confondus, et de $48 \%$ pour les stades B2, alors qu'elle était estimée à $11 \%$ en 1997 (2).

Le stade B2 (communément appelé « syndrome de Sézary »), est souvent considéré comme ayant un pronostic moins favorable par l'importance de sa charge tumorale sanguine. Cela a été démontré dans différentes études de survie selon le stade $\mathrm{B}$, avec une différence de survie 
significative entre les stades $\mathrm{B} 0$ et $\mathrm{B} 2$, et $\mathrm{B} 1$ et $\mathrm{B} 2$, mais rarement entre les stades $\mathrm{B} 0$ et $\mathrm{B} 1$ (6$10)$.

Concernant la survie spécifique, la différence entre les stades n'a pas pu être étudiée, du fait d'effectifs restreints, et de l'absence de décès imputable au lymphome dans le groupe B0. Mais les courbes de survie spécifique selon le stade semblent montrer une excellente survie spécifique à 5 ans dans le groupe B0 (100\%) et un taux de survie spécifique à 5 ans presque identique entre les stades B1 et B2, proche de 50\%. Dans notre étude, le stade sanguin initial n'avait pas d'impact sur la survie globale des patients, y compris après ajustement sur l'âge. Cela peut être expliqué par une performance accrue des traitements systémiques, permettant d'améliorer l'espérance de vie de ces patients.

D'autre part, la gradation en stades B ne semble pas représenter un continuum au cours de l'évolution des LTCE, car seuls 7,7\% de nos patients sont passés d'un stade à un autre, sur une durée médiane de suivi de 35,5 mois. Les patients ayant évolué ne semblaient pas montrer de différence significative dans leurs données clinico-biologiques initiales, comparés aux autres patients. Leur nombre de cellules de Sézary et de lymphocytes atypiques en particulier, ne semblaient pas plus élevés. Très peu d'auteurs ont étudié cette probabilité d'évolution entre les différents stades B, et seuls Hurabielle et al (11), en 2015, remarquent que certains de leurs patients B1 ont évolué vers un stade B2, mais aucun n'a évolué de B0 à B2. Cela est confirmé dans notre étude, puisqu'aucun de nos patients n'est passé du stade B0 à B2. Si cette tendance se confirmait dans de prochaines études, cela permettrait de rassurer les patients B0 dans leur prise en charge, avec une probabilité d'évoluer vers un stade avancé de la maladie presque nulle. Les résultats de notre étude sont limités par un petit échantillon de patients, ce qui peut expliquer l'absence de différence de survie significative entre les différents stades B, contrairement aux données de la littérature. D'autre part, notre recueil de données était rétrospectif, avec des données parfois manquantes, comme les résultats de l'immunophénotypage sanguin, ou le phénotype CD7, CD26, limitant l'analyse de leur impact pronostique. L'étude du CD158 n'étant que récemment disponible en pratique courante, de nombreux patients n'en avaient pas bénéficié au diagnostic.

Ces résultats restent intéressants pour notre pratique clinique, car ils permettent de confirmer qu'actuellement, les patients atteints de LTCE ont un pronostic moins sombre qu'il y a 20 ans, et que les différences de survie entre les stades sont peu importantes. Cela permet également de rassurer les patients initialement $\mathrm{B} 0$, sur le fait qu'ils ont une très faible probabilité d'évoluer vers un stade avancé d'atteinte tumorale sanguine, même si des études complémentaires sur des échantillons de plus grande taille seront nécessaires pour l'affirmer. 


\section{Annexes}

Tableau 1 : classification PROCLIPI proposée par I'EORTC

\begin{tabular}{|c|c|c|}
\hline \multirow[t]{2}{*}{ BO } & \multirow{2}{*}{$\begin{array}{l}\text { Cellules CD4+ CD7- ou CD26- } \\
<\mathbf{2 5 0 / \mu \mathrm { L }}\end{array}$} & a : clone T sanguin - \\
\hline & & $\mathrm{b}:$ clone $\mathrm{T}+$ \\
\hline \multirow[t]{2}{*}{ B1 } & \multirow{2}{*}{$\begin{array}{l}\text { Cellules CD4+ CD7- ou CD26- } \\
\text { entre } 250 \text { et } 1000 / \mu L\end{array}$} & a : clone T sanguin - \\
\hline & & $\mathrm{b}$ : clone T+ \\
\hline B2 & \multicolumn{2}{|c|}{$\begin{array}{l}\text { Cellules CD4+ CD7- ou CD26- >1000/ } \mu \mathrm{L} \text {, ou CD4/CD8 >10, ou CD4+ } \\
\text { CD7- >40\%, ou CD4+ CD26- >30\%, } \\
\text { Et clone } T+\end{array}$} \\
\hline
\end{tabular}


Tableau 2 : classification EORTC/ISCL 2007 des lymphomes cutanés de type MF/SS

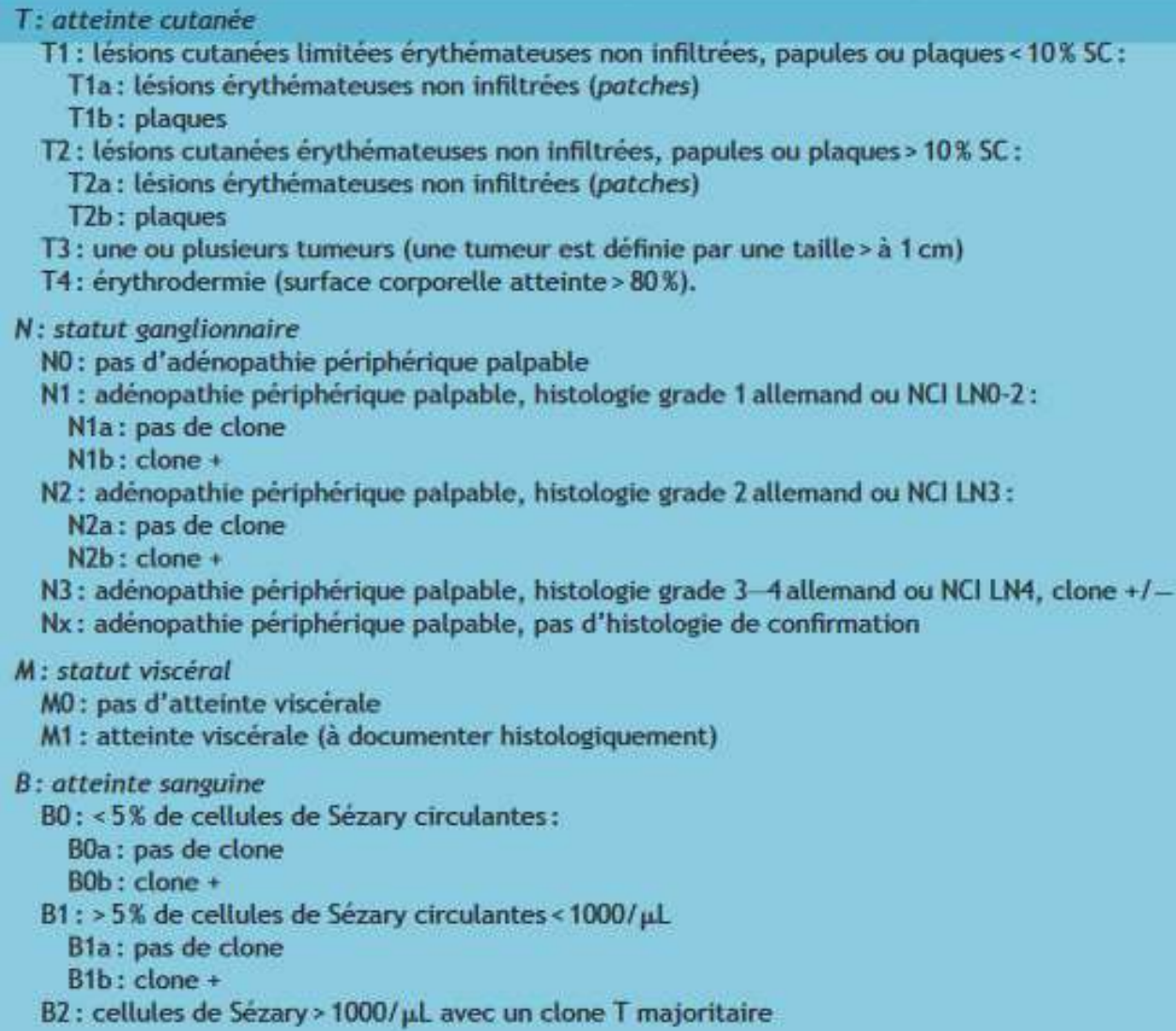

T1: lésions cutanées limitées érythémateuses non infiltrées, papules ou plaques < $10 \% \mathrm{SC}$ :

T1a: lésions érythémateuses non infiltrées (patches)

T1b: plaques

T2: lésions cutanées érythémateuses non infiltrées, papules ou plaques $>10 \% \mathrm{SC}$ :

T2a: lésions érythémateuses non infiltrées (patches)

T2b: plaques

T3: une ou plusieurs tumeurs (une tumeur est définie par une taille >à $1 \mathrm{~cm}$ )

T4: érythrodermie (surface corporelle atteinte $>80 \%$ ).

$N$ : statut ganglionnaire

NO: pas d'adénopathie périphérique palpable

N1 : adénopathie périphérique palpable, histologie grade 1 allemand ou NCI LNO-2:

N1a : pas de clone

$\mathrm{N} 1 \mathrm{~b}$ : clone +

N2 : adénopathie périphérique palpable, histologie grade 2 allemand ou NCI LN3:

N2a: pas de clone

$\mathrm{N} 2 \mathrm{~b}$ : clone +

N3 : adénopathie périphérique palpable, histologie grade 3-4allemand ou NCI LN4, clone +I-

$\mathrm{Nx}$ : adénopathie périphérique palpable, pas d'histologie de confirmation

$M$ : statut viscéral

MO: pas d'atteinte viscérale

M1 : atteinte viscérale (à documenter histologiquement)

B: atteinte sanguine

BO: $<5 \%$ de cellules de Sézary circulantes:

$\mathrm{BOa}$ : pas de clone

BOb: clone +

B1: $>5 \%$ de cellules de Sézary circulantes $<1000 / \mu \mathrm{L}$

B1a: pas de clone

B1b: clone +

B2 : cellules de Sézary $>1000 / \mu \mathrm{L}$ avec un clone T majoritaire

\begin{tabular}{|c|c|c|c|c|}
\hline Soit la stadification & $\mathrm{T}$ & $\mathrm{N}$ & M & B \\
\hline IA (plaques infiltrées ou non $<10 \%$ surface corporelle) & 1 & 0 & 0 & 0 \\
\hline IB (plaques infiltrées ou non $>10 \%$ surface corporelle) & 2 & 0 & 0 & 0 \\
\hline $\begin{array}{l}\text { IIA (plaques infiltrées ou non avec adénopathie } \\
\text { périphérique palpable, histologiquement non } \\
\text { spécifique) }\end{array}$ & 1,2 & 1,2 & 0 & 0 \\
\hline IIB (tumeurs) & 3 & 0 à 2 & 0 & 0 \\
\hline IIIA (érythrodermie sans envahissement sanguin) & 4 & 0 à 2 & 0 & 0 \\
\hline IIIB (érythrodermie avec envahissement sanguin timité) & 4 & 0 à 2 & 0 & 1 \\
\hline $\begin{array}{l}\text { IVA1 (envahissement sanguin important sans } \\
\text { adénopathie spécifique) }\end{array}$ & 1 à 4 & 0 à 2 & 0 & 2 \\
\hline IVA2 (adénopathie spécifique) & 1 à 4 & 3 & 0 & $0 \mathrm{a} 2$ \\
\hline IVB (atteinte viscérale) & 1 à 4 & 0 à 3 & 1 & 0 à 2 \\
\hline
\end{tabular}

SC: surface corporelle; EORTC: European Organization for Research and Treatment of Cancer; ISCL: International society for cutaneous lymphoma; MF: syndrome de Sézary; SS: syndrome de Sézary. 
Tableau 3 : caractéristiques clinico-biologiques des 52 patients, à la date du diagnostic

\begin{tabular}{|c|c|}
\hline & $\begin{array}{r}\text { Total } \\
(n=52)\end{array}$ \\
\hline Age au diagnostic (années) & $72,4 \pm 13,3$ \\
\hline Genre masculin & $30(57,7)$ \\
\hline Cellules Sézary/ $\mu \mathrm{L}$ & $348[46 ; 1400]$ \\
\hline $\mathrm{CD} 4 / \mathrm{CD} 8$ & $5,1[3,1 ; 15,2]$ \\
\hline $\mathrm{CD} 4 / \mathrm{CD} 8 \geq 10$ & $15 / 50(30,0)$ \\
\hline \multirow{2}{*}{ PCRTy $\begin{array}{l}\text { Clone } \\
\text { Clone s }\end{array}$} & $35 / 49(71,4)$ \\
\hline & $35 / 50(70,0)$ \\
\hline Identité clonale peau/sang & $19 / 44(43,2)$ \\
\hline $\begin{array}{l}\text { Nb lymphocytes atypiques } \\
(n=38)\end{array}$ & $125[0 ; 1354]$ \\
\hline Lymphocytes atypiques $>250 / \mu \mathrm{L}$ & $19 / 38(50,0)$ \\
\hline CD7- & $7 / 33(21,2)$ \\
\hline CD26- & $1 / 6(16,7)$ \\
\hline CD158+ & $2 / 4(50,0)$ \\
\hline \multicolumn{2}{|l|}{ Stade initial } \\
\hline B0a & $13(25,0)$ \\
\hline BOb & $13(25,0)$ \\
\hline B1a & $2(3,8)$ \\
\hline B1b & $9(17,3)$ \\
\hline B2 & $15(28,8)$ \\
\hline \multicolumn{2}{|l|}{ Stade initial } \\
\hline BO & $26(50,0)$ \\
\hline B1 & $11(21,2)$ \\
\hline B2 & $15(28,8)$ \\
\hline \multicolumn{2}{|c|}{$\begin{array}{l}\text { Les données sont présentées sous forme d'effectifs } \\
\text { (pourcentages), de moyenne } \pm \text { écart-type ou de médiane } \\
\text { [intervalle interquartile]. } \\
\text { CD7-, CD26-: nombre de patients avec perte d'expression } \\
\text { de ces marqueurs }\end{array}$} \\
\hline
\end{tabular}


Tableau 4 : facteurs clinico-biologiques associés à la survie globale des patients

\begin{tabular}{|c|c|c|c|c|}
\hline & \multicolumn{2}{|c|}{ Analyse non ajustée } & \multicolumn{2}{|c|}{ Analyse ajustée sur l'âge } \\
\hline & HR [IC 95\%] & $\mathbf{p}$ & HR [IC 95\%] & $\mathbf{p}$ \\
\hline Age au diagnostic (années) & $1,07[1,02 ; 1,13]$ & 0,011 & & \\
\hline Genre masculin & $0,92[0,34 ; 2,49]$ & 0,87 & $1,30[0,46 ; 3,67]$ & 0,62 \\
\hline Cellules Sézary/ $\mu \mathrm{L}$ & $1,02[0,85 ; 1,21]$ & 0,86 & $1,03[0,86 ; 1,22]$ & 0,76 \\
\hline CD4/CD8 & $1,34[0,79 ; 2,26]$ & 0,28 & $1,20[0,72 ; 1,98]$ & 0,49 \\
\hline $\mathrm{CD} 4 / \mathrm{CD} 8 \geq 10$ & $1,69[0,60 ; 4,77]$ & 0,32 & $1,65[0,58 ; 4,69]$ & 0,35 \\
\hline PCRT clone cutané + & $1,11[0,35 ; 3,54]$ & 0,86 & $1,42[0,44 ; 4,58]$ & 0,56 \\
\hline PCRT clone sanguin + & $1,86[0,52 ; 6,62]$ & 0,34 & $1,19[0,32 ; 4,44]$ & 0,80 \\
\hline Identité clonale peau/sang & $1,68[0,51 ; 5,54]$ & 0,39 & $1,67[0,51 ; 5,53]$ & 0,40 \\
\hline $\begin{array}{l}\text { Nb lymphocytes atypiques } \\
>250 / \mu \mathrm{L}\end{array}$ & $0,60[0,19 ; 1,90]$ & 0,38 & $0,80[0,24 ; 2,66]$ & 0,72 \\
\hline CD7- $(n=33)$ & $1,06[0,22 ; 5,13]$ & 0,94 & $0,97[0,20 ; 4,72]$ & 0,97 \\
\hline \multicolumn{5}{|l|}{ Stade initial } \\
\hline B0 & Référence & & Référence & \\
\hline B1 & $0,27[0,03 ; 2,09]$ & 0,21 & $0,43[0,05 ; 3,50]$ & 0,43 \\
\hline B2 & $0,85[0,29 ; 2,50]$ & 0,76 & $1,04[0,34 ; 3,13]$ & 0,95 \\
\hline
\end{tabular}

Les données sont présentées sous forme d'hazard ratio (HR) et intervalle de confiance (IC) à $95 \%$.

CD7- : perte d'expression du marqueur CD7 
Tableau 5 : caractéristiques clinico-biologiques des patients ayant changé de stade B au cours du suivi

\begin{tabular}{|c|c|c|}
\hline & $\begin{array}{r}\text { Pas d'évolution } \\
\qquad(n=31)\end{array}$ & $\begin{array}{r}\text { Evolution } \\
\qquad(n=6)\end{array}$ \\
\hline Age au diagnostic (années) & $74,8 \pm 13,9$ & $65,7 \pm 12,7$ \\
\hline Genre masculin & $18(58,1)$ & $5(83,3)$ \\
\hline Cellules Sézary/ $\mu \mathrm{L}(\mathrm{n}=36)$ & $120[0 ; 414]$ & $158[89 ; 250]$ \\
\hline CD4/CD8 (n=36) & $4,2[3,1 ; 7,4]$ & $2,5[1,8 ; 2,8]$ \\
\hline $\mathrm{CD} 4 / \mathrm{CD} 8 \geq 10$ & $5 / 30(16,7)$ & $0 / 6(0,0)$ \\
\hline Clone cutané + & $19 / 29(65,5)$ & $3 / 6(50,0)$ \\
\hline Clone sanguin + & $19 / 31(61,3)$ & $4 / 6(66,7)$ \\
\hline Identité clonale peau/sang & $8 / 27(29,6)$ & $1 / 5(20,0)$ \\
\hline $\begin{array}{l}\mathrm{Nb} \text { de lymphocytes atypiques } \\
>250 / \mu \mathrm{L}\end{array}$ & $7 / 24(29,2)$ & $1 / 3(33,3)$ \\
\hline \multicolumn{3}{|l|}{ Stade initial } \\
\hline BO & $23(74,2)$ & $3(50,0)$ \\
\hline B1 & $8(25,8)$ & $3(50,0)$ \\
\hline
\end{tabular}


Fig. 1 : diagramme de flux des patients de l'étude.

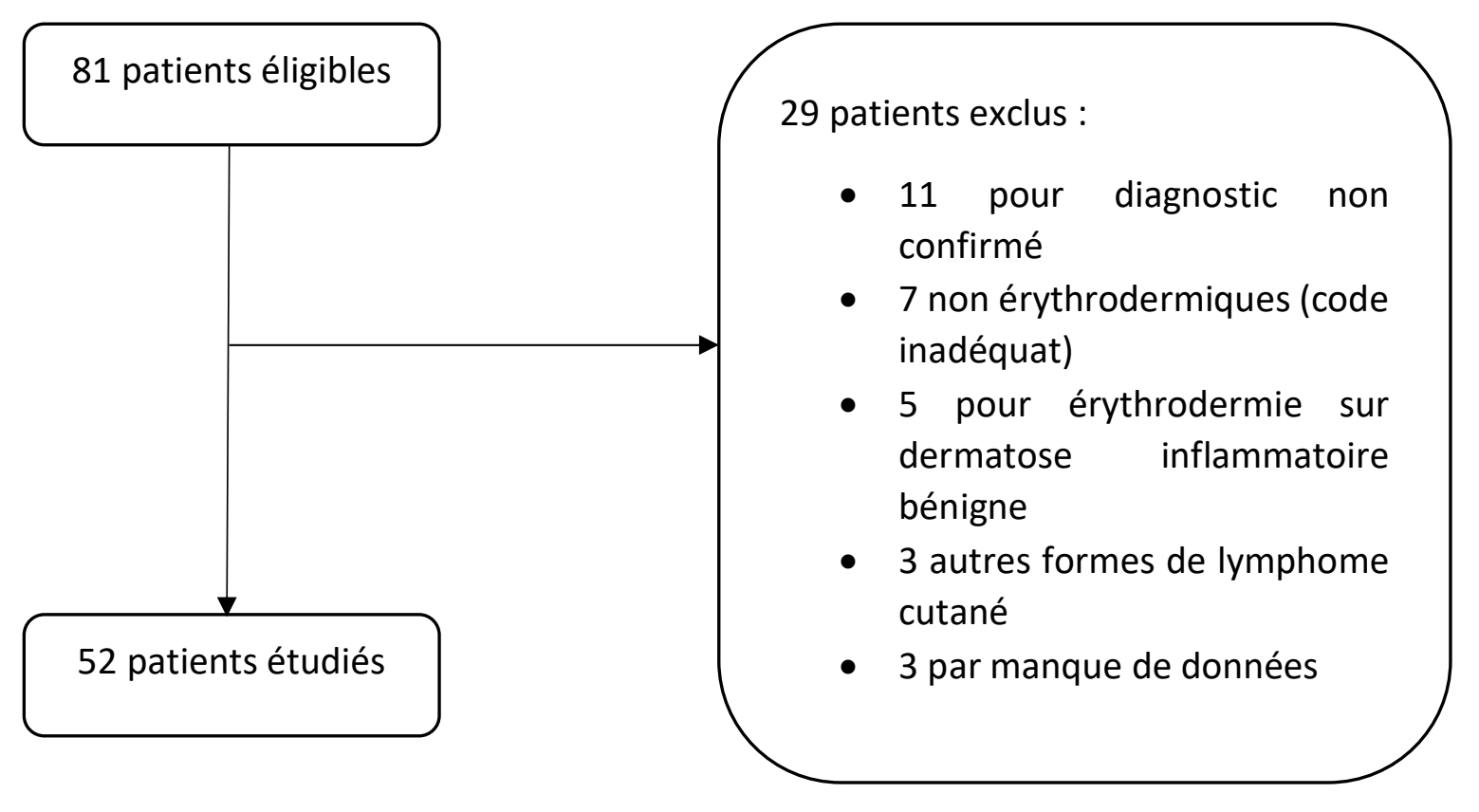

Fig. 2 : répartition des patients en stade $B$

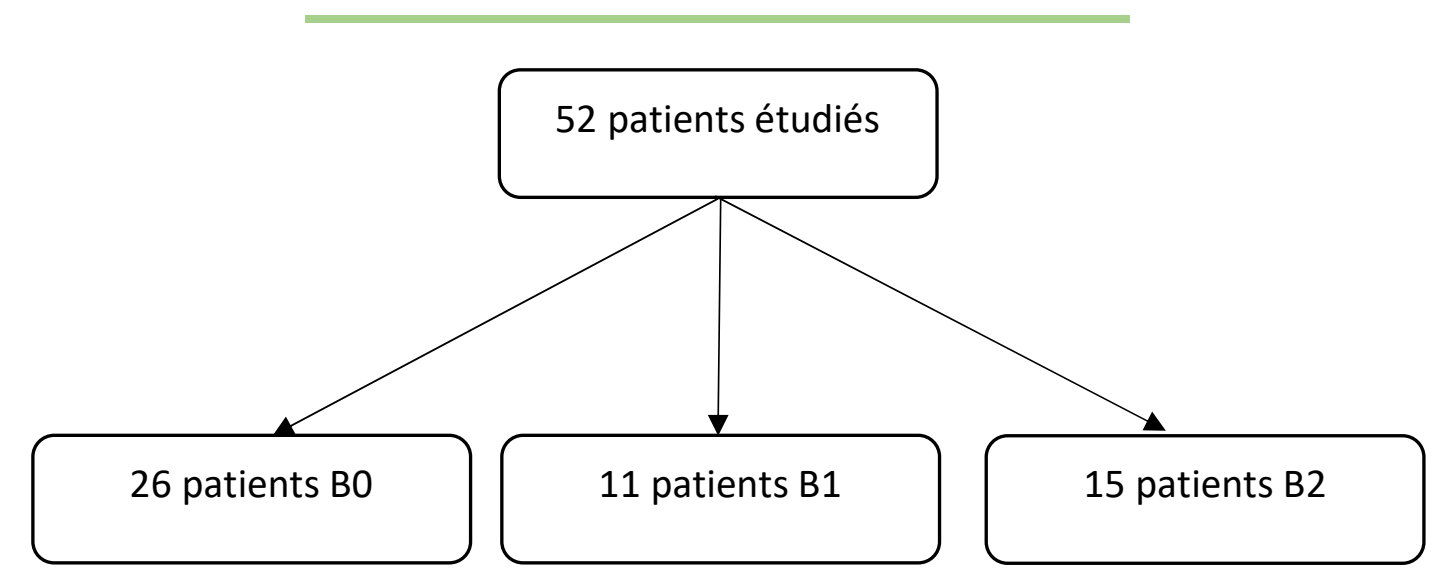


Fig. 3 : courbe de survie globale des 52 patients, quel que soit le stade B initial

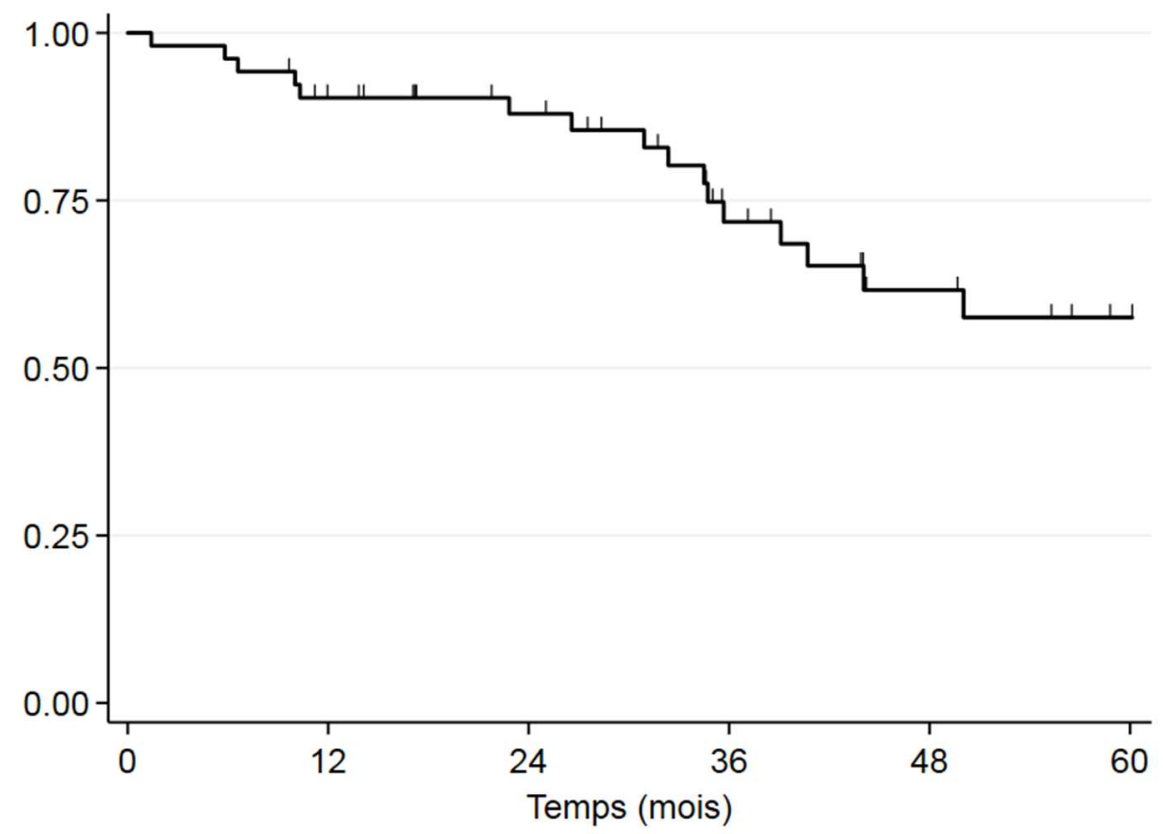

Fig. 4 : courbes de survie globale des 52 patients, selon le stade B initial

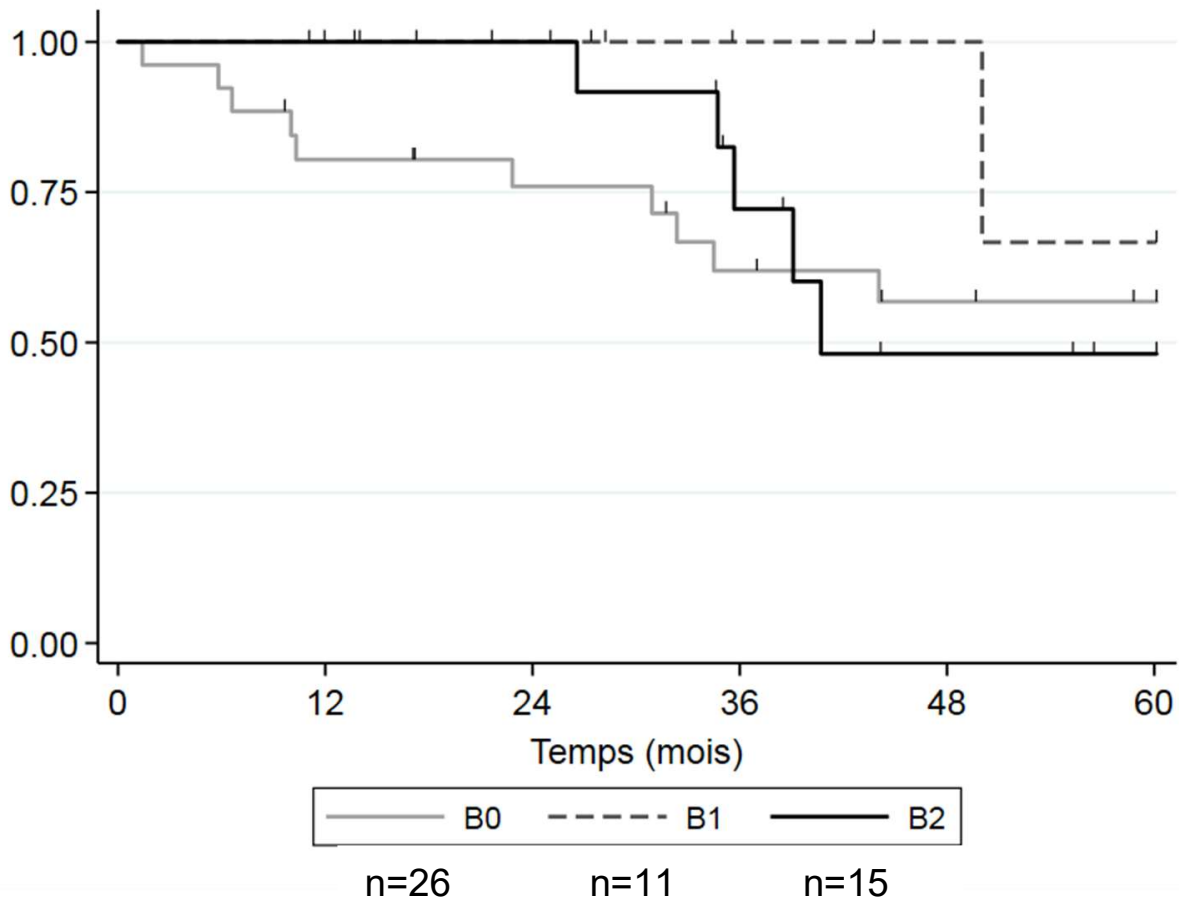


Fig. 5 : courbe de survie spécifique des 41 patients, quel que soit le stade B initial

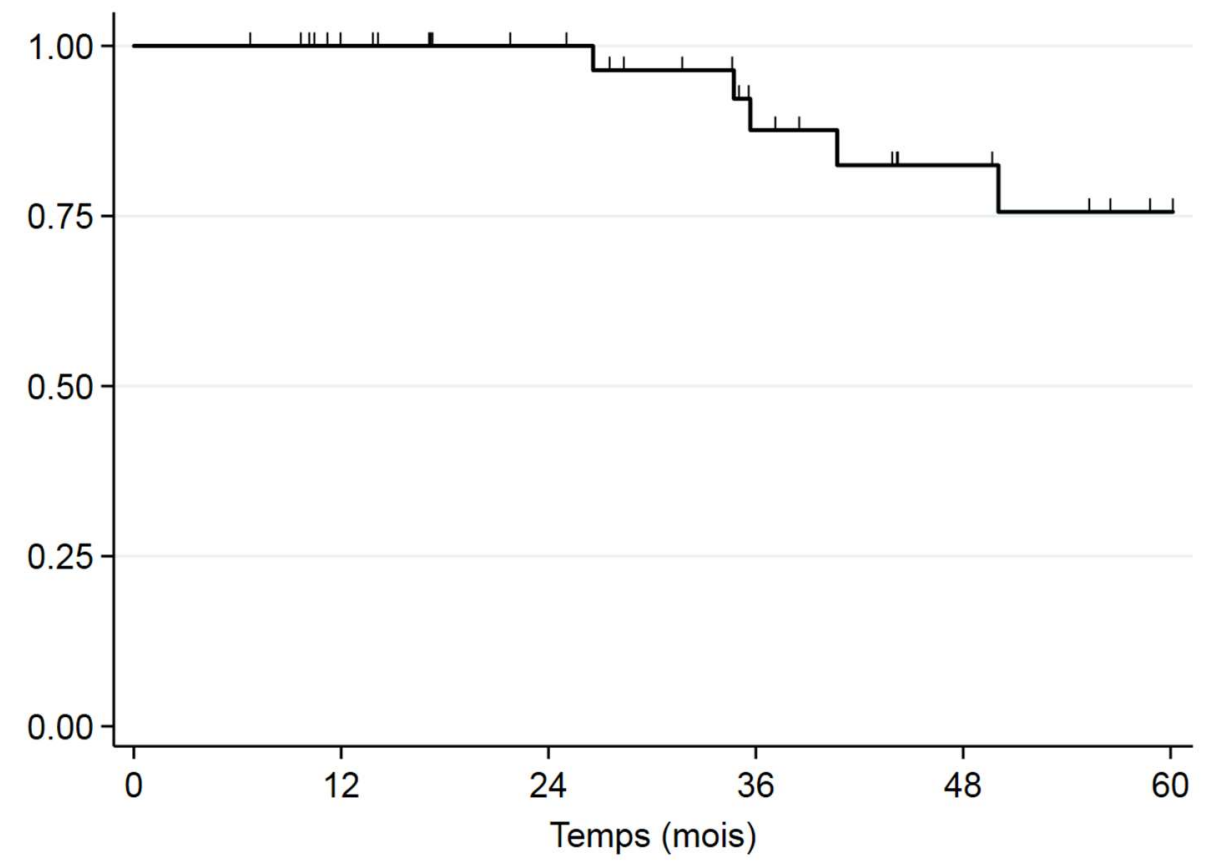

Fig.6 : courbes de survie spécifique des 41 patients, selon le stade B initial

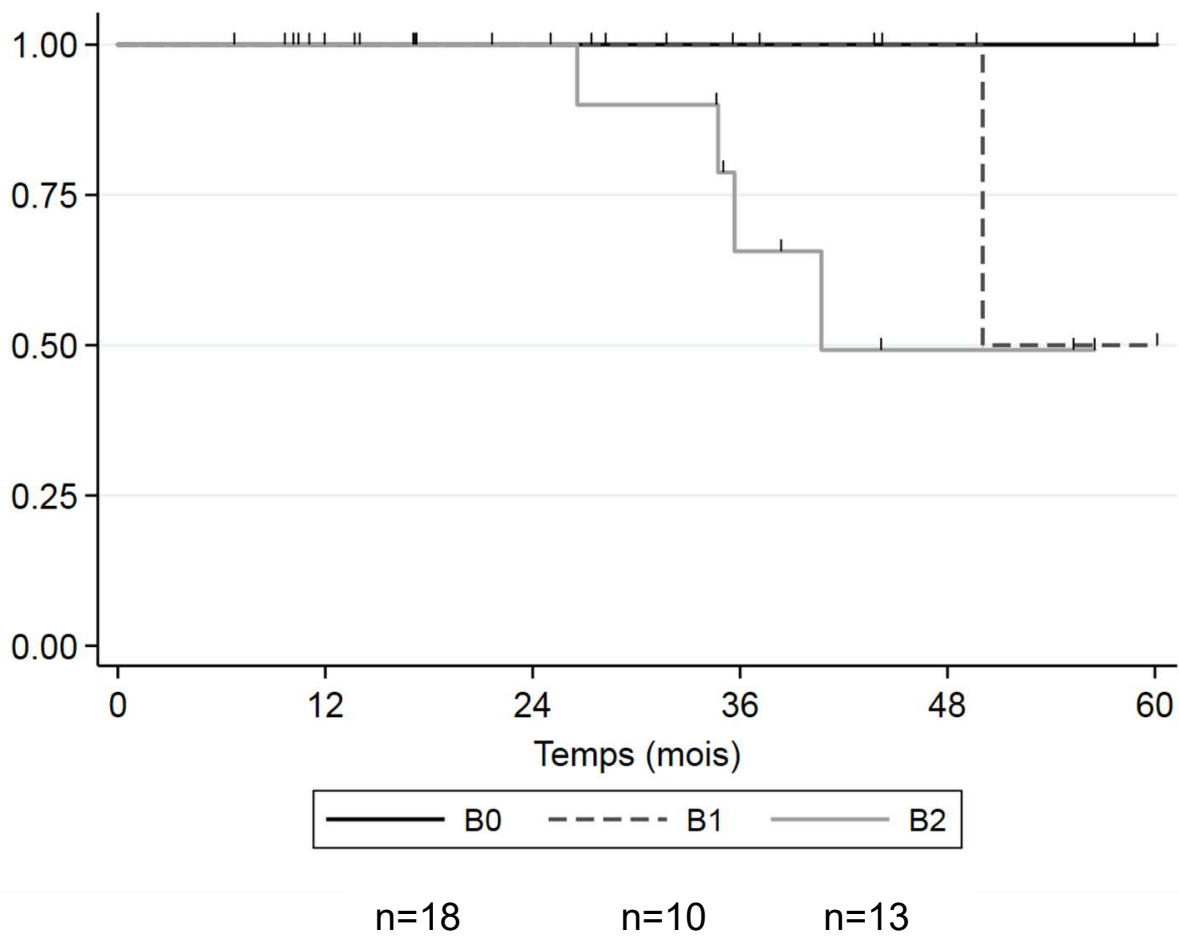




\section{Références}

1. Scarisbrick JJ, Hodak E, Bagot M, Stranzenbach R, Stadler R, Ortiz-Romero PL, et al. Blood classification and blood response criteria in mycosis fungoides and Sézary syndrome using flow cytometry: recommendations from the EORTC cutaneous lymphoma task force. Eur J Cancer. avr 2018;93:47-56.

2. Willemze R, Kerl H, Sterry W, Berti E, Cerroni L, Chimenti S, et al. EORTC classification for primary cutaneous lymphomas: a proposal from the Cutaneous Lymphoma Study Group of the European Organization for Research and Treatment of Cancer. Blood. 1 juill 1997;90(1):354-71.

3. Willemze R. WHO-EORTC classification for cutaneous lymphomas. Blood. 15 mai 2005;105(10):3768-85.

4. Diamandidou E, Colome M, Fayad L, Duvic M, Kurzrock R. Prognostic factor analysis in mycosis fungoides/Sézary syndrome. J Am Acad Dermatol. juin 1999;40(6):914-24.

5. Olsen E, Vonderheid E, Pimpinelli N, Willemze R, Kim Y, Knobler R, et al. Revisions to the staging and classification of mycosis fungoides and Sézary syndrome: a proposal of the International Society for Cutaneous Lymphomas (ISCL) and the cutaneous lymphoma task force of the European Organization of Research and Treatment of Cancer (EORTC). Blood. 15 sept 2007;110(6):1713-22.

6. Scarisbrick JJ, Whittaker S, Evans AV, Fraser-Andrews EA, Child FJ, Dean A, et al. Prognostic significance of tumor burden in the blood of patients with erythrodermic primary cutaneous T-cell lymphoma. Blood. 1 févr 2001;97(3):624-30.

7. Vidulich KA, Talpur R, Bassett RL, Duvic M. Overall survival in erythrodermic cutaneous T-cell lymphoma: an analysis of prognostic factors in a cohort of patients with erythrodermic cutaneous T-cell lymphoma. Int J Dermatol. mars 2009;48(3):243-52.

8. Agar NS, Wedgeworth E, Crichton S, Mitchell TJ, Cox M, Ferreira S, et al. Survival outcomes and prognostic factors in mycosis fungoides/Sézary syndrome: validation of the revised International Society for Cutaneous Lymphomas/European Organisation for Research and Treatment of Cancer staging proposal. J Clin Oncol Off J Am Soc Clin Oncol. 1 nov 2010;28(31):4730-9.

9. Talpur R, Singh L, Daulat S, Liu P, Seyfer S, Trynosky T, et al. Long-term Outcomes of 1,263 Patients with Mycosis Fungoides and Sezary Syndrome from 1982 to 2009. Clin Cancer Res. 15 sept 2012;18(18):5051-60.

10. Scarisbrick JJ, Prince HM, Vermeer MH, Quaglino P, Horwitz S, Porcu P, et al. Cutaneous Lymphoma International Consortium Study of Outcome in Advanced Stages of Mycosis Fungoides and Sézary Syndrome: Effect of Specific Prognostic Markers on Survival and Development of a Prognostic Model. J Clin Oncol. 10 nov 2015;33(32):3766-73.

11. Hurabielle C, Michel L, Ram-Wolff C, Battistella M, Jean-Louis F, Beylot-Barry M, et al. Expression of Sézary Biomarkers in the Blood of Patients with Erythrodermic Mycosis Fungoides. J Invest Dermatol. janv 2016;136(1):317-20. 
Conclusion 


\section{CONCLUSION DE LA THESE}

Les LTCE restent parfois de diagnostic difficile, même si nous possédons maintenant un large faisceau d'analyses cliniques, biologiques et moléculaires facilement réalisables en pratique, afin de les distinguer d'autres pathologies inflammatoires bénignes.

Le clinicien les classe par la suite en stade B0, B1 ou B2 selon l'importance de la charge tumorale sanguine au diagnostic. En pratique, la question du pronostic se pose rapidement chez ces patients, compte tenu de données de survie très sombres rapportées par la littérature. Néanmoins, comme nous l'avons vu dans notre étude, l'espérance de vie au diagnostic peut être très différente selon les patients, allant de 1 mois jusqu'à 18 ans. II semble donc important d'identifier des marqueurs biologiques et moléculaires, aisément réalisables en pratique quotidienne, permettant d'évaluer le pronostic des patients à long-terme. Notamment, les questions de la valeur pronostique de ce stade B initial, et de son impact sur la survie des patients se posent.

Dans notre étude portant sur 52 patients atteints d'un LTCE, la survie globale à 5 ans tous stades confondus est de 57,5\% et la survie spécifique à 5 ans de 75,6\%. II n'a cependant pas été retrouvé de différence de survie significative selon le stade B initial. La survie globale des LTCE, tous stades B confondus, semble s'améliorer au cours des années, selon les différentes études, ce qui est probablement expliqué par l'utilisation de nouveaux traitements, plus performants. Notre étude confirme cette tendance, avec des résultats de survie globale presque similaires à ceux de Klemke et al en 2015. (10) Le stade B2 (communément appelé « syndrome de Sézary "), est souvent considéré comme ayant un pronostic moins favorable par l'importance de sa charge tumorale sanguine. Cette différence de pronostic entre les stades B2 et les stades inférieurs n'a pas été mise en évidence dans notre étude, ce qui peut être expliqué par un manque de puissance, mais également par une

UFR de Médecine et des Professions Paramédicales

Service de la formation - Pôle 3

TSA 50400

28, Place Henri-Dunant 63001 Clermont-Ferrand Cedex 1 
amélioration des traitements. Plusieurs marqueurs biologiques (nombre de cellules de Sézary, de lymphocytes atypiques, ratio $C D 4 / C D 8$, perte d'expression de $C D 26, C D 7$ et $C D 158$ ) ont été étudiés ces dernières années, afin d'identifier des facteurs pronostiques indépendants dans les LTCE. Notre échantillon réduit de patients ne nous a pas permis de les mettre en évidence au sein de notre cohorte.

D’autre part, l'évolution d'un stade B à un autre a été très peu étudiée, souvent considérée comme un continuum au cours de l'évolution des LTCE. Hurabielle et al (42), en 2016, remarquent dans leur cohorte de patients que certains ont évolué d'un stade B1 vers un stade B2, mais aucun de BO à B2. Dans notre étude, seuls 4 patients ont changé de stade au cours du suivi, 2 étant passés de B0 à B1, et 2 de $B 1$ à $B 2$, mais aucun de $B 0$ à $B 2$, sans critère spécifique permettant de prédire cette évolution. Ces patients ne représentaient que $7,7 \%$ de notre cohorte, montrant que la charge tumorale sanguine des patients n'évolue donc que très rarement au cours du suivi. Cette donnée est rassurante pour la pratique clinique, même si elle doit être confirmée par des études de plus grande envergure.

Plusieurs lignes de traitement sont disponibles pour la prise en charge des LTCE. Hormis l'allogreffe de cellules souches, aucun traitement ne permet actuellement une rémission complète et durable de la maladie. Plusieurs molécules sont en développement, notamment ciblées sur des marqueurs spécifiques de la maladie, comme le KIR3DL2. Ces traitements pourraient permettre d'assister encore à une amélioration significative du pronostic chez ces patients atteints de lymphome cutané T érythrodermique.

Clermont-Ferrand, le 22/10/2020

Pierre CLAVELOU

Doyens-Directeur

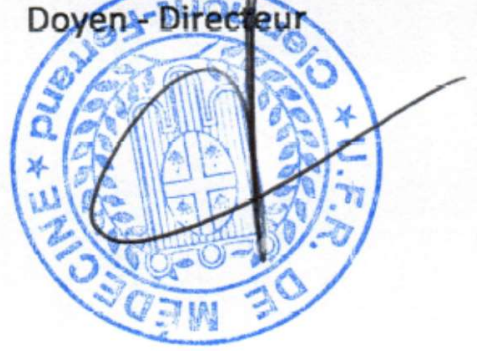

UFR de Médecine et des Professions Paramédicales Clermont-Ferrand, le 1510912 Le Président ou Jury Service de la formation - Pôle 3 TSA 50400 28, Place Henri-Dunant 63001 Clermont-Ferrand Cedex 1

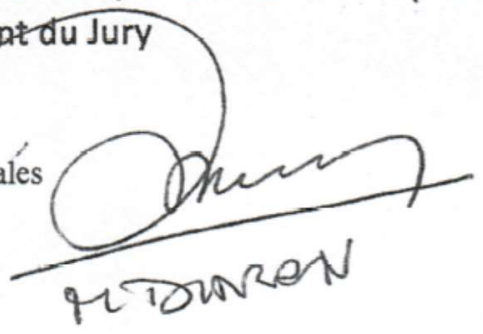




\section{REFERENCES}

1. Willemze R. WHO-EORTC classification for cutaneous lymphomas. Blood. 15 mai 2005;105(10):3768-85.

2. Olsen E, Vonderheid E, Pimpinelli N, Willemze R, Kim Y, Knobler R, et al. Revisions to the staging and classification of mycosis fungoides and Sézary syndrome: a proposal of the International Society for Cutaneous Lymphomas (ISCL) and the cutaneous lymphoma task force of the European Organization of Research and Treatment of Cancer (EORTC). Blood. 15 sept 2007;110(6):1713-22.

3. Bagot $\mathrm{M}$, Ortonne N. Lymphomes cutanés : classification. WwwemPremiumcomdatatraitesde298-60771 [Internet]. 23 oct 2012 [cité 8 déc 2019]; Disponible sur: https://www-em-premium-com.ezproxy.uca.fr/article/723136

4. Ram-Wolff C, Laroche L, Wechsler J. Mycosis fongoïde érythrodermique et syndrome de Sézary. In: Les lymphomes cutanés. Bagot et al. Paris: Springer-Verlag; 2013. p. 77-91.

5. Mangold AR, Thompson AK, Davis MD, Saulite I, Cozzio A, Guenova E, et al. Early clinical manifestations of Sézary syndrome: A multicenter retrospective cohort study. J Am Acad Dermatol. oct 2017;77(4):719-27.

6. Russell-Jones R. Diagnosing erythrodermic cutaneous T-cell lymphoma. Br J Dermatol. juill 2005;153(1):1-5.

7. Spicknall KE. Sézary syndrome-clinical and histopathologic features, differential diagnosis, and treatment. Semin Cutan Med Surg. mars 2018;37(1):18-23.

8. Vonderheid EC. On the diagnosis of erythrodermic cutaneous T-cell lymphoma. J Cutan Pathol. févr 2006;33(S1):27-42.

9. Nagler AR, Samimi S, Schaffer A, Vittorio CC, Kim EJ, Rook AH. Peripheral blood findings in erythrodermic patients: Importance for the differential diagnosis of S?zary syndrome. J Am Acad Dermatol. mars 2012;66(3):503-8.

10. Klemke CD, Booken N, Weiss C, Nicolay JP, Goerdt S, Felcht M, et al. Histopathological and immunophenotypical criteria for the diagnosis of Sézary syndrome in differentiation from other erythrodermic skin diseases: a European Organisation for Research and Treatment of Cancer (EORTC) Cutaneous Lymphoma Task Force Study of 97 cases. Br J Dermatol. 2015;173(1):93-105.

11. Klemke C-D, Brade J, Weckesser S, Sachse MM, Booken N, Neumaier M, et al. The diagnosis of Sezary syndrome on peripheral blood by flow cytometry requires the use of multiple markers. $\mathrm{Br}$ J Dermatol. 1 sept 2008;159:871-80.

12. Vonderheid EC, Bernengo MG, Burg G, Duvic M, Heald P, Laroche L, et al. Update on erythrodermic cutaneous T-cell lymphoma: report of the International Society for Cutaneous Lymphomas. J Am Acad Dermatol. janv 2002;46(1):95-106.

13. Vonderheid EC, Pena J, Nowell P. Sézary cell counts in erythrodermic cutaneous T-cell Iymphoma: Implications for prognosis and staging. Leuk Lymphoma. janv 2006;47(9):1841-56. 
14. Bernengo MG, Novelli $M$, Quaglino $P$, Lisa F, Matteis $A D$, Savoia $P$, et al. The relevance of the CD41 CD26 \pm subset in the identification of circulating SeÂzary cells. Br J Dermatol. 2001;11.

15. Novelli M, Comessatti A, Quaglino P, Savoia P, Fierro MT, Bernengo MG. CD26 Expression on Cutaneous Infiltrates from Patients with Cutaneous T-Cell Lymphoma (CTCL). In: Back N, Cohen IR, Kritchevsky D, Lajtha A, Paoletti R, éditeurs. Dipeptidyl Aminopeptidases in Health and Disease [Internet]. Boston: Kluwer Academic Publishers; 2004 [cité 9 avr 2020]. p. 223-34. (Advances in Experimental Medicine and Biology; vol. 524). Disponible sur: http://link.springer.com/10.1007/0-306-47920-6_27

16. Jones D, Dang NH, Duvic M, Washington LT, Huh YO. Absence of CD26 Expression Is a Useful Marker for Diagnosis of T-Cell Lymphoma in Peripheral Blood. Am J Clin Pathol. juin 2001;115(6):885-92 .

17. Vonderheid EC, Hou JS. CD4+CD26- lymphocytes are useful to assess blood involvement and define B ratings in cutaneous T cell lymphoma. Leuk Lymphoma. juin 2017;59(2):330-9.

18. Bouaziz J-D, Remtoula N, Bensussan A, Marie-Cardine A, Bagot M. Absolute CD3+ CD158k+ lymphocyte count is reliable and more sensitive than cytomorphology to evaluate blood tumour burden in Sézary syndrome. Br J Dermatol. janv 2010;162(1):123-8.

19. Poszepczynska-Guigné $E$, Schiavon $V$, $D^{\prime}$ Incan $M$, Echchakir $H$, Musette $P$, Ortonne $N$, et al. CD158k/KIR3DL2 Is a New Phenotypic Marker of Sezary Cells: Relevance for the Diagnosis and Follow-Up of Sezary Syndrome. J Invest Dermatol. mars 2004;122(3):820-3.

20. Hurabielle $C$, Thonnart N, Ram-Wolff $C$, Sicard H, Bensussan A, Bagot M, et al. Usefulness of KIR3DL2 to Diagnose, Follow-Up, and Manage the Treatment of Patients with Sézary Syndrome. Clin Cancer Res. 15 juill 2017;23(14):3619-27.

21. Bensussan A, Janela B, Thonnart N, Bagot M, Musette P, Ginhoux F, et al. Identification of CD39 as a Marker for the Circulating Malignant T-Cell Clone of Sézary Syndrome Patients. J Invest Dermatol. mars 2019;139(3):725-8.

22. Kirsch IR, Watanabe R, O'Malley JT, Williamson DW, Scott L-L, Elco CP, et al. TCR sequencing facilitates diagnosis and identifies mature T cells as the cell of origin in CTCL. Sci Transl Med. 7 oct 2015;7(308):308ra158-308ra158.

23. Beylot-Barry M, Sibaud V, Thiebaut R, Vergier B, Beylot C, Delaunay $M$, et al. Evidence that an Identical T Cell Clone in Skin and Peripheral Blood Lymphocytes is an Independent Prognostic Factor in Primary Cutaneous T Cell Lymphomas. J Invest Dermatol. 1 oct 2001;117(4):920-6.

24. Larocca C, Kupper T. Mycosis Fungoides and Sézary Syndrome. Hematol Oncol Clin North Am. févr 2019;33(1):103-20.

25. Cocks M, Porcu P, Wick MR, Gru AA. Recent Advances in Cutaneous T-cell Lymphoma. Surg Pathol Clin. sept 2019;12(3):783-803.

26. Weed J, Gibson J, Lewis J, Carlson K, Foss F, Choi J, et al. FISH Panel for Leukemic CTCL. J Invest Dermatol. mars 2017;137(3):751-3.

27. Willemze R, Cerroni L, Kempf W, Berti E, Facchetti F, Swerdlow SH, et al. The 2018 update of the WHO-EORTC classification for primary cutaneous lymphomas. Blood. 18 avr 2019;133(16):1703-14. 
28. Stadler R, Stranzenbach R. Molecular pathogenesis of cutaneous lymphomas. Exp Dermatol. oct 2018;27(10):1078-83.

29. Miyashiro D, Sanches JA. Erythroderma: a prospective study of 309 patients followed for 12 years in a tertiary center. Sci Rep. 17 juin 2020;10(1):9774.

30. Scarisbrick J, Quaglino P, Prince HM, Papadavid E, Vermeer M, Hodak E, et al. The PROCLIPI study; a prototype registry for rare disease with global collaboration for establishment of a prognostic index in mycosis fungoides and Sezary syndrome. Eur J Cancer. sept 2018;101:S6.

31. Scarisbrick JJ, Hodak E, Bagot M, Stranzenbach R, Stadler R, Ortiz-Romero PL, et al. Blood classification and blood response criteria in mycosis fungoides and Sézary syndrome using flow cytometry: recommendations from the EORTC cutaneous lymphoma task force. Eur J Cancer. avr 2018;93:47-56.

32. Martinez XU, Di Raimondo C, Abdulla FR, Zain J, Rosen ST, Querfeld C. Leukaemic variants of cutaneous T-cell lymphoma: Erythrodermic mycosis fungoides and Sézary syndrome. Best Pract Res Clin Haematol. sept 2019;32(3):239-52.

33. Hristov AC, Tejasvi T, Wilcox RA. Mycosis fungoides and Sézary syndrome: 2019 update on diagnosis, risk-stratification, and management. Am J Hematol. sept 2019;94(9):1027-41.

34. Scarisbrick JJ, Kim YH, Whittaker SJ, Wood GS, Vermeer MH, Prince HM, et al. Prognostic factors, prognostic indices and staging in mycosis fungoides and Sézary syndrome: where are we now? $\mathrm{Br}$ J Dermatol. juin 2014;170(6):1226-36.

35. Willemze R, Kerl H, Sterry W, Berti E, Cerroni L, Chimenti S, et al. EORTC classification for primary cutaneous lymphomas: a proposal from the Cutaneous Lymphoma Study Group of the European Organization for Research and Treatment of Cancer. Blood. 1 juill 1997;90(1):354-71.

36. Bernengo MG, Quaglino P, Novelli M, Cappello N, Doveil GC, Lisa F, et al. Prognostic factors in Sézary syndrome: A multivariate analysis of clinical, haematological and immunological features. Ann Oncol. août 1998;9(8):857-63.

37. Scarisbrick JJ, Whittaker S, Evans AV, Fraser-Andrews EA, Child FJ, Dean A, et al. Prognostic significance of tumor burden in the blood of patients with erythrodermic primary cutaneous Tcell lymphoma. Blood. 1 févr 2001;97(3):624-30.

38. Vidulich KA, Talpur R, Bassett RL, Duvic M. Overall survival in erythrodermic cutaneous T-cell lymphoma: an analysis of prognostic factors in a cohort of patients with erythrodermic cutaneous T-cell lymphoma. Int J Dermatol. mars 2009;48(3):243-52.

39. Agar NS, Wedgeworth E, Crichton S, Mitchell TJ, Cox M, Ferreira S, et al. Survival outcomes and prognostic factors in mycosis fungoides/Sézary syndrome: validation of the revised International Society for Cutaneous Lymphomas/European Organisation for Research and Treatment of Cancer staging proposal. J Clin Oncol Off J Am Soc Clin Oncol. 1 nov 2010;28(31):4730-9.

40. Kubica AW, Davis MDP, Weaver AL, Killian JM, Pittelkow MR. Sézary syndrome: A study of 176 patients at Mayo Clinic. J Am Acad Dermatol. déc 2012;67(6):1189-99.

41. Talpur R, Singh L, Daulat S, Liu P, Seyfer S, Trynosky T, et al. Long-term Outcomes of 1,263 Patients with Mycosis Fungoides and Sezary Syndrome from 1982 to 2009. Clin Cancer Res. 15 sept 2012;18(18):5051-60. 
42. Scarisbrick JJ, Prince HM, Vermeer MH, Quaglino P, Horwitz S, Porcu P, et al. Cutaneous Lymphoma International Consortium Study of Outcome in Advanced Stages of Mycosis Fungoides and Sézary Syndrome: Effect of Specific Prognostic Markers on Survival and Development of a Prognostic Model. J Clin Oncol. 10 nov 2015;33(32):3766-73.

43. Hurabielle $C$, Michel L, Ram-Wolff C, Battistella M, Jean-Louis F, Beylot-Barry $M$, et al. Expression of Sézary Biomarkers in the Blood of Patients with Erythrodermic Mycosis Fungoides. J Invest Dermatol. janv 2016;136(1):317-20.

44. Tancrède-Bohin $E$, Ionescu MA, Salmonière $P$ de L, Dupuy $A$, Rivet J, Rybojad $M$, et al. Prognostic Value of Blood Eosinophilia in Primary Cutaneous T-Cell Lymphomas. Arch Dermatol. 1 sept 2004;140(9):1057-61.

45. Diamandidou E, Colome M, Fayad L, Duvic M, Kurzrock R. Prognostic factor analysis in mycosis fungoides/Sézary syndrome. J Am Acad Dermatol. juin 1999;40(6):914-24.

46. Lebowitz E, Geller S, Flores E, Pulitzer M, Horwitz S, Moskowitz A, et al. Survival, disease progression and prognostic factors in elderly patients with mycosis fungoides and Sézary syndrome: a retrospective analysis of 174 patients. J Eur Acad Dermatol Venereol JEADV. janv 2019;33(1):108-14.

47. Vonderheid EC, Kantor GR, Telang GH, Bujanouskas P, Kadin ME. A histo-immunopathologic and prognostic study of erythrodermic cutaneous T-cell lymphoma. J Cutan Pathol. déc 2019;46(12):913-24.

48. Benton EC, Crichton S, Talpur R, Agar NS, Fields PA, Wedgeworth E, et al. A cutaneous lymphoma international prognostic index (CLIPi) for mycosis fungoides and Sezary syndrome. Eur J Cancer. sept 2013;49(13):2859-68.

49. Vonderheid EC, Bernengo MG. The Sézary syndrome: hematologic criteria. Hematol Clin. 1 déc 2003;17(6):1367-89.

50. Battistella M, Leboeuf C, Ram-Wolff C, Hurabielle C, Bonnafous C, Sicard H, et al. KIR3DL2 expression in cutaneous T-cell lymphomas: expanding the spectrum for KIR3DL2 targeting. Blood. 28 2017;130(26):2900-2.

51. Su M, Dorocicz I, Dragowska WH, Ho V, Li G, Voss N, et al. Aberrant Expression of T-Plastin in Sezary Cells. Cancer Res. 1 nov 2003;63(21):7122-7.

52. Tang N, Gibson H, Germeroth T, Porcu P, Lim HW, Wong HK. T-plastin ( PLS3 ) gene expression differentiates Sézary syndrome from mycosis fungoides and inflammatory skin diseases and can serve as a biomarker to monitor disease progression. $\mathrm{Br} J$ Dermatol. févr 2010;162(2):463-6.

53. Boonk SE, Zoutman WH, Putter H, Ram-Wolff C, Felcht M, Klemke C-D, et al. Increased Expression of PLS3 Correlates with Better Outcome in Sézary Syndrome. J Invest Dermatol. mars 2017;137(3):754-7. 


\section{SERMENT D'HIPPOCRATE}

Au moment d'être admis(e) à exercer la médecine, je promets et je jure d'être fidèle aux lois de l'honneur et de la probité.

Mon premier souci sera de rétablir, de préserver ou de promouvoir la santé dans tous ses éléments, physiques et mentaux, individuels et sociaux.

Je respecterai toutes les personnes, leur autonomie et leur volonté, sans aucune discrimination selon leur état ou leurs convictions. J'interviendrai pour les protéger si elles sont affaiblies, vulnérables ou menacées dans leur intégrité ou leur dignité. Même sous la contrainte, je ne ferai pas usage de mes connaissances contre les lois de l'humanité.

J'informerai les patients des décisions envisagées, de leurs raisons et de leurs conséquences. Je ne tromperai jamais leur confiance et n'exploiterai pas le pouvoir hérité des circonstances pour forcer les consciences.

Je donnerai mes soins à l'indigent et à quiconque me les demandera. Je ne me laisserai pas influencer par la soif du gain ou la recherche de la gloire.

Admis(e) dans l'intimité des personnes, je tairai les secrets qui me seront confiés. Reçu(e) à l'intérieur des maisons, je respecterai les secrets des foyers et ma conduite ne servira pas à corrompre les moeurs.

Je ferai tout pour soulager les souffrances. Je ne prolongerai pas abusivement les agonies. Je ne provoquerai jamais la mort délibérément. 
Je préserverai l'indépendance nécessaire à l'accomplissement de ma mission. Je n'entreprendrai rien qui dépasse mes compétences. Je les entretiendrai et les perfectionnerai pour assurer au mieux les services qui me seront demandés.

J'apporterai mon aide à mes confrères ainsi qu'à leurs familles dans l'adversité.

Que les hommes et mes confrères m'accordent leur estime si je suis fidèle à mes promesses ; que je sois déshonoré(e) et méprisé(e) si j’y manque. 


\section{SERMENT D'HIPPOCRATE}

En présence des Maîtres de cette FACULTE et de mes chers CONDISCIPLES, je promets et je jure d'être fidèle aux lois de l'Honneur et de la Probité dans l'exercice de la Médecine.

Je donnerai mes soins gratuits à l'indigent et je n'exigerai jamais un salaire au-dessus de mon travail. Admis dans l'intérieur des maisons, mes yeux ne verront pas ce qui s'y passe, ma langue taira les secrets qui me seront confiés et mon état ne servira pas à corrompre les moeurs ni à favoriser le crime.

Respectueux et reconnaissant envers mes MAÎTRES, je rendrai à leurs enfants l'instruction que j'ai reçue de leurs pères.

Que les HOMMES m'accordent leur estime si je suis fidèle à mes promesses. Que je sois couvert d'OPPROBRE et méprisé de mes confrères si j'y manque. 


\section{Pronostic des lymphomes T cutanés érythrodermiques}

CONTEXTE : en 2005, le consortium EORTC/ISCL intègre les lymphomes T cutanés érythrodermiques (LTCE) au sein de sa classification. Selon l'importance de la charge tumorale circulante, ils sont classés en stades BO (" mycosis fongoïde érythrodermique »), B1 (" pré-Sézary) ou B2 (« maladie de Sézary »). Leur pronostic est diversement apprécié selon les études, mais il tend à s'améliorer ces dernières années, notamment pour les patients B2. De nombreux travaux ont tenté d'identifier des facteurs, ou combinaisons de facteurs pronostiques, mais peu d'entre eux ont spécifiquement analysé la valeur pronostique du stade B initial, pourtant utilisé au quotidien par le clinicien.

OBJECTIF : I'objectif principal de notre étude est d'étudier la valeur pronostique du stade B initial, chez les patients atteints d'un lymphome T cutané érythrodermique. L'objectif secondaire est d'étudier la pertinence d'autres facteurs pronostiques retrouvés dans la littérature, et d'évaluer le risque de passage d'un stade $B$ à un autre au cours du suivi.

METHODE : tous les patients suivis au CHU de Clermont-Ferrand entre 2000 et 2018, et présentant une érythrodermie associée une histologie cutanée compatible avec un lymphome T cutané épidermotrope ont été inclus. Les patients ont été rétrospectivement classés B0, B1 ou B2 selon les critères PROCLIPI. La survie (globale et spécifique) de la population totale et de chaque groupe a été estimée par la méthode de KaplanMeier, depuis la date du diagnostic jusqu'au décès, ou jusqu'à la date des dernières nouvelles.

RESULTATS : 52 patients ont été inclus, dont 26 classés B0, 11 classés B1 et 15 classés B2. La survie globale à 5 ans tous stades confondus était de $57,5 \%$, et la survie spécifique à 5 ans de $75,6 \%$. La survie globale à 5 ans des patients B2 était de $48 \%$. II n'a pas été retrouvé de différence significative de survie globale selon le stade B initial. Quatre patients ont changé de stade B au cours du suivi, 2 sont passés de B0 à B1 et 2 de B1 à B2.

CONCLUSION : la survie globale des LTCE, et notamment des stades B2, semble s'améliorer au cours des années, selon les différentes études de survie, ce qui est probablement expliqué par l'utilisation de nouveaux traitements, plus performants. Notre étude confirme cette tendance, avec une survie globale à 5 ans de $57,5 \%$ tous stades confondus, et de $48 \%$ pour les stades B2, alors qu'elle était estimée à $11 \%$ en 1997 . D'autre part, la gradation en stades $B$ ne semble pas représenter un continuum au cours de l'évolution des LTCE, car seuls $7,7 \%$ de nos patients sont passés d'un stade à un autre, sur une durée médiane de suivi de 35,5 mois.

Mots clés : lymphome T cutané, syndrome de Sézary, érythrodermie, classification sanguine, évolution, pronostic, survie globale et spécifique 